\title{
Drug transporters and blood-testis barrier function
}

\author{
Linlin Su, Dolores D Mruk, Will M Lee ${ }^{\mathbf{1}}$ and $\mathrm{C}$ Yan Cheng \\ The Mary M. Wohlford Laboratory for Male Contraceptive Research, Center for Biomedical Research, Population Council, 1230 York Avenue, \\ New York, New York 10065, USA \\ ${ }^{1}$ School of Biological Sciences, The University of Hong Kong, Hong Kong, China \\ (Correspondence should be addressed to C Y Cheng; Email: y-cheng@popcbr.rockefeller.edu)
}

\begin{abstract}
The blood-testis barrier (BTB) creates an immunological barrier that segregates the seminiferous epithelium into the basal and apical compartment. Thus, meiosis I/II and postmeiotic germ cell development take place in a specialized microenvironment in the apical compartment behind the BTB and these events are being shielded from the host immune system. If unwanted drugs and/or chemicals enter the apical compartment from the microvessels in the interstitium via the basal compartment, efflux pumps (e.g. P-glycoprotein) located in Sertoli cells and/or spermatids can actively transport these molecules out of the apical compartment. However, the mechanism(s) by which influx pumps regulate the entry of drugs/chemicals into the apical compartment is not known. In this study, a solute carrier (SLC) transporter organic anion transporting polypeptide 3 (Oatp3, Slco1a5) was shown to be an integrated component of the N-cadherin-based adhesion
\end{abstract}

complex at the BTB. However, a knockdown of Oatp3 alone or in combination with three other major Sertoli cell drug influx pumps, namely Slc22a5, Slco6b1, and Slco6c1, by RNAi using corresponding specific siRNA duplexes failed to perturb the Sertoli cell tight junction (TJ) permeability barrier function. Yet, the transport of $\left[{ }^{3} \mathrm{H}\right]$ adjudin, a potential male contraceptive that is considered a toxicant to spermatogenesis, across the BTB was impeded following the knockdown of either Oatp3 or all the four SLC transporters. In short, even though drug transporters (e.g. influx pumps) are integrated components of the adhesion protein complexes at the BTB, they are not involved in regulating the Sertoli cell TJ permeability barrier function, instead they are only involved in the transport of drugs, such as adjudin, across the immunological barrier at the BTB.

Journal of Endocrinology (2011) 209, 337-351

\section{Introduction}

The blood-testis barrier (BTB) created by adjacent Sertoli cells near the basement membrane in the seminiferous epithelium of the testis maintains one of the tightest barrier-tissue barriers in the mammalian body, which segregates the entire events of i) meiosis I and meiosis II and ii) post-meiotic spermatid development, namely spermiogenesis and spermiation, from the systemic circulation (Cheng \& Mruk 2002, 2010, O’Donnell et al. 2011). Thus, developing germ cells must rely on Sertoli cells for structural and nutritional support in the seminiferous epithelium (Mruk et al. 2008). The BTB also imposes an immunological barrier to prevent unwanted and harmful substances from reaching the microenvironment in the apical compartment restricted for spermatid development and by shielding meiotic and haploid germ cells from being recognized and attacked by the host immune system because many specific antigens are expressed transiently in these developing germ cells (Mruk et al. 2008, Cheng \& Mruk 2010, Cheng et al. 2011). Additionally, the BTB plays an important role to confer the testis the immune-privileged status (Meinhardt \& Hedger 2010). However, this unique barrier also creates a major hurdle in drug development for male contraception and treatment of testicular cancer (e.g. germ cell tumors) if these drugs exert their effects behind the BTB (Mruk \& Cheng 2008). Thus, there is much interest to investigate the role of drug transporters, such as efflux pumps (e.g. P-glycoprotein) and influx pumps (e.g. organic anion transporting polypeptides (Oatps, including Oatp1, Oatp2, Oatp3 (Slco1a5), and Oatp4), which are members of a solute carrier (SLC) transporter subfamily), in regulating drug trafficking across blood-tissue barriers, in particular, at the blood-brain barrier and the blood-retinal/ocular barrier (Dallas et al. 2006, Miller et al. 2008). Recent studies have identified several drug transporters in the testis (Suzuki et al. 2003, Augustine et al. 2005, Su et al. 2009). For instance, P-glycoprotein was shown to be an integrated component of the occludin-, claudin-11-, and JAM-A-based adhesion protein complexes at the BTB, and a significant but transient increase in their association was also detected when rats were treated with adjudin (1-(2,4-dichlorobenzyl)-1H-indazole-3-carbohydrazide (Su et al. 2009), a potential male contraceptive known to exert its effects at the Sertoli-spermatid interface by disrupting the apical ectoplasmic specialization (apical ES, a testis-specific atypical adherens junction type) anchoring device to induce 
spermatid loss from the seminiferous epithelium (Cheng \& Mruk 2002, Mruk et al. 2008, Wong et al. 2008a)). We interpret that this surge in the steady-state protein level of P-glycoprotein and its increase in association with the adhesion protein complexes at the BTB (Su et al. 2009) are likely used by the testes to 'pump' adjudin, a toxicant to spermatogenesis, out of the apical compartment in the seminiferous epithelium to protect post-meiotic spermatid development. Thus, we sought to examine whether Oatp3 (Slco1a5; Meier \& Stieger 2002, Klaassen \& Aleksunes 2010, Su et al. 2010b, Ueno et al. 2010) - a widely expressed influx drug pump known to transport thyroid hormones, prostaglandin $\mathrm{E}_{2}$, organic anions and signal mediators across the blood-brain barrier (Abe et al. 1998, Ohtsuki et al. 2004) and bile acid across the gut barrier in intestine (Cattori et al. 2001) and is found in the testis (Augustine et al. 2005, Su et al. 2009) - was structurally associated with integral membrane proteins at the BTB. We also investigated whether Oatp3 (Slco1a5 alone, or in combination with other SLC transporters (influx pumps), such as Slc22a5 (a SLC organic cation transporter family member 5 , also known as OCTN2, a $\mathrm{Na}^{+}$-dependent organic cation/carnitine transporter 2, involved in the transport of carnitine and organic cations), Slco6b1 (a SLC organic anion transporter family member 6b1, also known as a testis-specific transporter-1 (TST-1), or GST1, gonad-specific transporter, implicated in Schwann cell development and involved in the transport of dehydroepiandrosterone sulfate, sex steroids and thyroid hormones), and Slco6c1 (a SLC organic anion transporter family member 6c1, also known as TST-2 or GST-2, involved in the transport of thyroxine, taurocholic acid, and dehydroepiandrosterone), which are highly expressed in Sertoli cells in the testis (Collarini et al. 1992, Mizuno et al. 2003, Suzuki et al. 2003, Augustine et al. 2005, Ueno et al. 2010) and are known to be involved in drug transports in epithelia under normal and pathological conditions (Rochat 2009, Kis et al. 2010,
Klaassen \& Aleksunes 2010), would regulate the entry of drugs (e.g. adjudin) from the basal to the apical compartment across the BTB. We also assessed whether the entry of adjudin into the epithelium behind the BTB is mediated by changes in the Sertoli cell tight junction (TJ) permeability barrier if Slco1a5 is a structural component of the adhesion protein complexes at the BTB.

\section{Materials and Methods}

\section{Animals}

The use of Sprague-Dawley rats in all the experiments reported in this study was approved by the Rockefeller University Animal Care and Use Committee with Protocol Numbers 06018 and 09016.

\section{Antibodies}

Antibodies were either obtained commercially or prepared in our laboratory and the appropriate working dilutions are listed in Table 1. All commercially purchased antibodies are known to cross-react with the corresponding proteins in rats as indicated by the manufacturers.

\section{Primary Sertoli cell cultures}

Primary Sertoli cells were isolated from 20-day-old rat testes and cultured in F12/DMEM supplemented with growth factors and bacitracin as described earlier (Cheng et al. 1986, Mruk et al. 2003, Su et al. 2009). Sertoli cells were plated on Matrigel (BD Biosciences, Bedford, MA, USA)-coated 12 -well culture plates at i) $0.5 \times 10^{6}$ cells $/ \mathrm{cm}^{2}$ for lysate preparation or for RNA extraction and ii) $0 \cdot 05 \times 10^{6}$ cells/ $\mathrm{cm}^{2}$ on coverslips for dual-labeled immunofluorescence (IF)

Table 1 Primary antibodies used for different experiments in this report

\begin{tabular}{|c|c|c|c|c|c|}
\hline Target protein & Catalog no. & Lot no. & Host & Vendor & Usage \\
\hline Oatp3 & sC-47265 & A1408 & Goat & Santa Cruz Biotechnology & IB $(1: 200)$, IHC (1:50), IF (1:50), IP (1:40) \\
\hline OatpY & SC- 102045 & G1608 & Rabbit & Santa Cruz Biotechnology & IB $(1: 200)$ \\
\hline \multirow[t]{2}{*}{ P-glycoprotein } & 517310 & D00087822 & Mouse & Calbiochem (San Diego, CA, USA) & IB $(1: 300)$ \\
\hline & SC-55510 & B1108 & Mouse & Santa Cruz Biotechnology & IF $(1: 50)$ \\
\hline Mrp1 & sC- 13960 & 11906 & Rabbit & Santa Cruz Biotechnology & IB $(1: 200)$ \\
\hline Claudin-11 & $36-4500$ & $387613 \mathrm{~A}$ & Rabbit & Zymed/Invitrogen & IB $(1: 250)$, IF $(1: 50)$ \\
\hline JAM-A & $36-1700$ & $463126 A$ & Rabbit & Zymed/Invitrogen & IB $(1: 250)$, IF $(1: 50)$ \\
\hline $\mathrm{ZO}-1$ & $61-7300$ & $450085 A$ & Rabbit & Zymed/Invitrogen & IB $(1: 250)$, IF $(1: 50)$ \\
\hline Occludin & $71-1500$ & $636024 \mathrm{~A}$ & Rabbit & Zymed/Invitrogen & IB $(1: 250)$, IF $(1: 50)$ \\
\hline $\mathrm{N}$-cadherin & sc-7939 & H0907 & Rabbit & Santa Cruz Biotechnology & IB $(1: 200)$, IF $(1: 50)$ \\
\hline$\beta$-Catenin & $71-2700$ & $60806848 C 2$ & Rabbit & Zymed/Invitrogen & IB $(1: 250)$, IF $(1: 50)$ \\
\hline FAK & $06-543$ & 31701 & Rabbit & Upstate (Billerica, MA, USA) & IB $(1: 1000)$ \\
\hline $\mathrm{C}-\mathrm{SrC}$ & SC- 8056 & D0408 & Mouse & Santa Cruz Biotechnology & IB $(1: 200)$ \\
\hline Laminin $\beta 3$ & - & - & Rabbit & Cheng Lab (Yan \& Cheng 2006) & IF $(1: 75)$ \\
\hline Laminin $\gamma^{3}$ & - & - & Rabbit & Cheng Lab (Yan \& Cheng 2006) & IF $(1: 75)$ \\
\hline$\beta 1$-Integrin & 610468 & 02070 & Mouse & BD Biosciences & IF $(1: 50)$ \\
\hline Actin & sc-1616 & F0809 & Goat & Santa Cruz Biotechnology & IB $(1: 200)$ \\
\hline
\end{tabular}

IB, immunoblotting; IHC, immunohistochemistry; IF, immunofluorescence microscopy; IP, immunoprecipitation. 
analysis or plated at iii) $1.2 \times 10^{6}$ cells $/ \mathrm{cm}^{2}$ on Matrigelcoated Millicell bicameral units to assess the Sertoli cell TJ permeability barrier by quantifying transepithelial electrical resistance (TER) across the cell epithelium and for $\left[{ }^{3} \mathrm{H}\right]$ adjudin transport assay. It is noted that Sertoli cells cultured on Matrigel-coated dishes or bicameral units is known to establish a functional $\mathrm{TJ}$ permeability barrier (Grima et al. 1992, 1998, Lui et al. 2001) with ultrastructures of TJ, basal ES, and desmosome when examined by electron microscopy (Siu et al. 2005), which mimics the BTB in vivo (Byers et al. 1986, Janecki \& Steinberger 1986, Mruk et al. 1997). This in vitro system has widely been used by investigators in the field to study Sertoli cell BTB regulation (Janecki et al. 1991a, 1992, Okanlawon \& Dym 1996) including our laboratory (Lui et al. 2001, Wong et al. 2008b, Yan et al. 2008b, Siu et al. 2009a). Also, Sertoli cells isolated from 20-day-old rat testes are fully differentiated and ceased to divide (Orth 1982), and these cells are functionally indistinguishable from adult Sertoli cells isolated from adult rat testes (Li et al. 2001a, Lui et al. 2003a).

\section{Drug transporters knockdown in Sertoli cell epithelium by RNAi}

For RNAi experiments, Sertoli cells were transfected with $100 \mathrm{nM}$ non-targeting control siRNA or specific Oatp3 (Slco1a5) siRNA duplexes (Ambion/Applied Biosystems, Austin, TX, USA, see Table 2) for Oatp3 single knockdown; $200 \mathrm{nM}$ non-targeting control duplexes, a mixture of $50 \mathrm{nM}$ Slco $1 a 5$ plus $150 \mathrm{nM}$ control siRNA duplexes or a mixture of Slco1a5, Slc22a5, Slco6b1, and Slco6c1 siRNA duplexes (50 nM each) in multiple influx drug transporters (MIDTs) knockdown experiments using RiboJuice siRNA Transfection Reagent (Novagen/EMD4 Biosciences, San Diego, CA, USA). The sequences of the four drug transporters' siRNA duplexes are listed in Table 2. The sequences of the non-targeting control siRNA duplexes (Silencer Select Negative Number 1 siRNA) were not available from the manufacturer (Ambion), but the Catalog number is listed in Table 2. Transfection was performed routinely on day 3 when an intact Sertoli cell epithelium with a functional TJ permeability barrier was established as described earlier (Li et al. 2009, Lie et al. 2010). About $24 \mathrm{~h}$ thereafter, transfection mixture was removed and replaced with fresh F12/DMEM, and cells were cultured for another $48 \mathrm{~h}$ before their termination. In dual-labeled IF analysis, siGLO Red Transfection Indicator (Dharmacon/Thermo Fisher Scientific, Lafayette, CO, USA) was co-transfected with specific siRNA duplexes to confirm successful transfection. Off-target effects of the silencing experiments were assessed by immunoblot analysis using multiple marker proteins at the BTB including two efflux pumps: P-glycoprotein and multidrug resistance-associated protein 1 (Mrp1).

Administration of adjudin to adult rats and in vitro treatment of Sertoli cells with adjudin

Adjudin $(50 \mathrm{mg} / \mathrm{kg}$ b.w., suspended in $0.5 \%$ methylcellulose (wt/vol) ) was administered to adult rats $(\approx 300 \mathrm{~g}$ b.w. $)$ by gavage with a single dose to induce germ cell loss from the seminiferous epithelium (Cheng et al. 2001, Su et al. 2009). Rats were killed by $\mathrm{CO}_{2}$ asphyxiation at selected time points at $0,3,6,9$, and $12 \mathrm{~h}$, and 1,2 and 4 days after treatment $(n=3-5$ rats per time point), testes were removed immediately under aseptic conditions, snap-frozen in liquid nitrogen and stored at $-80^{\circ} \mathrm{C}$ until used. Testis lysate was obtained for immunoblot analysis as described (Su et al. 2010c). Cross-sections $(7 \mu \mathrm{m}$ thick) of testes were obtained with a cryostat at $-20{ }^{\circ} \mathrm{C}$ and used for immunohistochemistry (IHC; Su et al. 2010a, Siu et al. 2011). For Sertoli cell cultures, adjudin $(1 \mu \mathrm{g} / \mu \mathrm{l}$ stock, dissolved in ethanol) was added to F12/DMEM at a final concentration of $1 \mu \mathrm{g} / \mathrm{ml}$. Sertoli cells were treated with media containing adjudin daily and terminated for dual-labeled IF analysis at specified time points.

\section{$\left.P^{3} H\right] a d j u d i n$ transport assay in Sertoli cell epithelium with a functional BTB that mimics the BTB in vivo}

$\left[{ }^{3} \mathrm{H}\right]$ adjudin [indazole-5,7- $\left.{ }^{3} \mathrm{H}(\mathrm{N})\right]-1-(2,4-$ dichlorobenzyl)$1 \mathrm{H}$-indazole-3-carbohydrazide, specific activity, $580 \mathrm{mCi} /$ mmol) was obtained from Perkin Elmer (Boston, MA, USA). The purity of this radiolabeled adjudin was shown to be at least $98 \%$ pure by reverse-phase HPLC using a Zorbax SB-C18 HPLC column $(4 \cdot 6 \times 250 \mathrm{~mm}$ i.d.). Sertoli cells were cultured on Matrigel-coated bicameral units at $1 \cdot 2 \times$ $10^{6} \mathrm{cells} / \mathrm{cm}^{2}$ for 3 days to form an intact epithelium with a functional TJ permeability barrier established when assessed by TER across the cell epithelium and having the

Table 2 Primers of siRNA duplexes used for RNAi experiments to knockdown different drug transporters (influx pumps) ${ }^{\mathrm{a}}$

\begin{tabular}{ll} 
Gene & sirNA sequence (sense) \\
\cline { 1 - 1 } Oatp3 (Slco1a5) & 5'-GCAUUGGAUAUUUACUUAUtt-3' \\
& 5'-GUAUCAAGCCUGAAGAGAAtt-3' \\
Slc22a5 & 5'-CAGCAGAGUGUAUAAAAGAtt-3' \\
S/co6b1 & 5'-CCUUAGGAGUUUGCAUAUUtt-3' \\
Slco6c1 & 5'-GGACCACUGCUUUUUCGAAtt-3' \\
& 5'-CAGUUGCAAUUACGAAAUUtt-3'
\end{tabular}

siRNA sequence (anti-sense)

$$
\begin{aligned}
& \text { 5'-AUAAGUAAAUAUCCAAUGCat-3' } \\
& \text { 5'-UUCUCUUCAGGCUUGAUACac-3' } \\
& \text { 5'-UCUUUUAUACACUCUGCUGgg-3' } \\
& \text { 5'-AAUAUGCAAACUCCUAAGGtg-3' } \\
& \text { 5'-UUCGAAAAAGCAGUGGUCCag-3' } \\
& \text { 5'-AAUUUCGUAAUUGCAACUGtc-3' }
\end{aligned}
$$

SiRNA ID no.

s135280

s135282

s135281

s132113

s139506

s142031

${ }^{a}$ Sequences for the non-targeting control duplexes (Silencer Select Negative Number 1 siRNA, Cat. no. 4390843) are not available from the manufacturer (Ambion). 
Table 3 Primers used for RT-PCR

\begin{tabular}{|c|c|c|c|c|c|c|c|}
\hline Gene & Primer sequence & Orientation & Position & $\begin{array}{l}\text { Length } \\
\text { (bp) }\end{array}$ & $\begin{array}{l}\text { GenBank } \\
\text { accession no. }\end{array}$ & $\begin{array}{l}\text { Cycle } \\
\text { no. }\end{array}$ & $T_{\mathbf{m}}\left({ }^{\circ} \mathrm{C}\right)$ \\
\hline $\begin{array}{l}\text { Oatp3 } \\
\quad \text { (Slco1a5) }\end{array}$ & $\begin{array}{l}\text { 5'-GGAGAAACAGAGAAAAGGGT-3' } \\
\text { 5'-ATCCAACTATAGATGTGGGG-3' }^{\prime}\end{array}$ & $\begin{array}{l}\text { Sense } \\
\text { Anti-sense }\end{array}$ & $\begin{array}{r}4-23 \\
178-159\end{array}$ & 175 & NM_030838 & 25 & 53 \\
\hline Slc22a5 & $\begin{array}{l}\text { 5'-TGGTGTGTAAGGATGACTGGAA-3' } \\
5^{\prime} \text {-CCAACAAGGACAAAAAGCACT-3' }\end{array}$ & $\begin{array}{l}\text { Sense } \\
\text { Anti-sense }\end{array}$ & $\begin{array}{l}401-422 \\
591-611\end{array}$ & 211 & NM_019269 & 25 & 55 \\
\hline Slco6b1 & $\begin{array}{l}5^{\prime} \text {-CATCAGAGTATTCCCTTATCA-3' } \\
5^{\prime} \text {-CAGAACGAGATAAGAAAGAAG-3' }\end{array}$ & $\begin{array}{l}\text { Sense } \\
\text { Anti-sense }\end{array}$ & $\begin{array}{l}249-269 \\
429-449\end{array}$ & 201 & NM_133412 & 25 & 52 \\
\hline
\end{tabular}

ultrastructures of TJ, basal ES, and desmosome-like junction when examined by electron microscopy as described (Siu et al. 2005). Thereafter, Sertoli cells were transfected with nontargeting control siRNA duplexes, Slco1a5 siRNA duplexes, or a mixture of Slco $1 a 5$, Slc22a5, Slco6b1, and Slco6c1 siRNA duplexes for quadruple knockdown. siRNA duplexes were removed $24 \mathrm{~h}$ thereafter, and 3 days after transfection, $\left[{ }^{3} \mathrm{H}\right]$ adjudin $\left(\sim 0.6 \times 10^{6}\right.$ c.p.m. $)$ was added to the basal compartment of each bicameral unit. About $50 \mu$ aliquot of F12/DMEM was withdrawn from the apical or basal compartment at selected time points: $0,0 \cdot 5,1 \cdot 5,3,4,5,6$, 7 , and $9 \mathrm{~h}$ and placed in scintillation vials together with $3 \mathrm{ml}$ liquid scintillation cocktail (Beckman Coulter Inc., Brea, CA, USA) for radioactivity determination using a $\beta$-counter.

\section{Immunoblot analysis and co-immunoprecipitation}

Lysates from testes or Sertoli cells were prepared in immunoprecipitation (IP) lysis buffer $(10 \mathrm{mM}$ Tris, $0 \cdot 15 \mathrm{M}$ $\mathrm{NaCl}, 1 \% \mathrm{NP}-40$, and $10 \%$ glycerol, $\mathrm{pH} 7 \cdot 4$ at $22{ }^{\circ} \mathrm{C}$ ) supplemented with protease and phosphatase inhibitor cocktails (Sigma-Aldrich) according to the manufacturer's instructions as described earlier ( $\mathrm{Su}$ et al. 2009). Lysates $(\sim 100 \mu \mathrm{g}$ protein from testes or $50 \mu \mathrm{g}$ from Sertoli cells) were resolved by SDS-PAGE for immunoblot analysis with target proteins being probed by the corresponding primary antibodies (Table 1) as described earlier (Su et al. 2009, 2010c). Protein estimation was performed by spectrophotometry with a Bio-Rad Dc Protein Assay Kit using BSA as a standard and a Bio-Rad Model 680 Plate Reader. Co-immunoprecipitation (Co-IP) was performed to identify proteins that are structurally associated with Slco1a5 as described ( $\mathrm{Su}$ et al. 2009). In brief, $2 \mu \mathrm{g}$ normal goat IgG was added to $300 \mu \mathrm{g}$ lysates of Sertoli cells, incubated for an hour before precipitated with $10 \mu \mathrm{l}$ protein $\mathrm{A} / \mathrm{G}$ agarose beads $(1 \mathrm{~h})$, and the supernatant was obtained $(1000 \mathrm{~g}, 5 \mathrm{~min})$. This precleaning step removed non-specific interacting proteins from the cell lysates. Thereafter, lysates were incubated with $2 \mu \mathrm{g}$ normal goat IgG as negative control or specific anti-Oapt3 antibody for Co-IP on a Labnet MiniLabRoller overnight, to be followed by incubation with $20 \mu \mathrm{l}$ protein $\mathrm{A} / \mathrm{G}$ agarose beads (Santa Cruz Biotechnology, Santa Cruz, CA, USA) to extract the immunocomplexes. Thereafter, beads were washed with IP lysis buffer and immunocomplexes (Slco1a5 and its interacting protein partners) were extracted in an SDS-PAGE sample buffer at $100{ }^{\circ} \mathrm{C}$ for SDS-PAGE and immunoblot analysis. Sertoli cell lysate $(20 \mu \mathrm{g}$ protein) without IP served as a positive control.

\section{IHC and dual-labeled IF analysis}

IHC and dual-labeled IF analysis were performed essentially as described earlier (Wong et al. 2008b, Yan et al. 2008a, Su et al. 2009). Frozen sections of testes ( $\sim 7 \mu$ thick) were obtained with a cryostat and fixed with Bouin's fixative. Cultured Sertoli cells were fixed with $4 \%$ paraformaldehyde in PBS (10 mM sodium phosphate, $0 \cdot 15 \mathrm{M} \mathrm{NaCl}, \mathrm{pH} 7 \cdot 4$ at $22{ }^{\circ} \mathrm{C}$ ). Primary antibodies were incubated at room temperature

Table 4 Primers used for real-time PCR (qPCR)

\begin{tabular}{|c|c|c|c|c|c|c|c|}
\hline Gene & Primer sequence & Orientation & Position & $\begin{array}{l}\text { Length } \\
\text { (bp) }\end{array}$ & $\begin{array}{l}\text { GenBank } \\
\text { accession no. }\end{array}$ & $\begin{array}{r}\text { Cycle } \\
\text { no. }\end{array}$ & $\boldsymbol{T}_{\mathbf{m}}\left({ }^{\circ} \mathrm{C}\right)$ \\
\hline \multirow{2}{*}{$\begin{array}{l}\text { Oatp3 } \\
\quad \text { (Slco1a5) }\end{array}$} & 5'-ACСТTCTGTATTTCTTGC-3' & Sense & $1196-1213$ & \multirow[t]{2}{*}{88} & \multirow[t]{2}{*}{ NM_030838 } & \multirow[t]{2}{*}{40} & \multirow[t]{2}{*}{60} \\
\hline & 5'-GGGTGGTGAACTCCTT-3' & Anti-sense & $1268-1283$ & & & & \\
\hline \multirow[t]{2}{*}{ Slc22a5 } & 5'-CGССТTCСАСТАТСТTC-3' & Sense & $923-939$ & \multirow[t]{2}{*}{96} & \multirow[t]{2}{*}{ NM_019269 } & \multirow[t]{2}{*}{40} & \multirow[t]{2}{*}{60} \\
\hline & 5'-TATTTCGTGTTCGGACC-3' & Anti-sense & $1002-1018$ & & & & \\
\hline \multirow[t]{2}{*}{ Slco6b1 } & $5^{\prime}$-TATGGTCTGGGTTATGC- $3^{\prime}$ & Sense & $949-965$ & \multirow[t]{2}{*}{97} & \multirow[t]{2}{*}{ NM_133412 } & \multirow[t]{2}{*}{40} & \multirow[t]{2}{*}{60} \\
\hline & 5'-ACTGCCACCAAAGAAA- $3^{\prime}$ & Anti-sense & 1030-1045 & & & & \\
\hline \multirow[t]{2}{*}{ Slco6c1 } & 5'-AACCCGCTGCTGATGA-3' & Sense & 1093-1108 & \multirow[t]{2}{*}{88} & \multirow[t]{2}{*}{ NM_173338 } & \multirow[t]{2}{*}{40} & \multirow[t]{2}{*}{60} \\
\hline & 5'-GCAAGTGGTAAGGCAGAA-3' & Anti-sense & $1163-1180$ & & & & \\
\hline
\end{tabular}


overnight at appropriate dilutions (see Table 1). Secondary antibodies from SuperPicture HRP Polymer Conjugate Kit for goat primary antibody (Invitrogen) for IHC or secondary antibodies appropriately conjugated with either FITC-488 or CY3-555 (Invitrogen) for IF microscopy were used. Images were captured using an Olympus BX61 fluorescence microscope with an Olympus DP71 (at 12.5 megapixel) digital camera and Olympus MicroSuite Five imaging software package to obtain the TIFF file format. All images were subsequently compiled and analyzed using Adobe Creative Suite CS3 software package, such as for image overlay. Each IHC and dual-labeled IF analysis experiment was repeated at least three times using different rat testis and/or Sertoli cell preparations. Thus, representative results from at least three independent experiments were shown herein.

\section{Functional assessment of the Sertoli cell TJ permeability barrier}

The Sertoli cell TJ permeability barrier was quantified by the ability of the cell epithelium to restrict the current flow (ohm) transmitted across the cell monolayer when two electrodes of a Millipore Millicell-ERS were placed in the corresponding apical and basal chamber of the bicameral unit (Millipore, Bedford, MA, USA), and a short ( 2 seconds) $20 \mu \mathrm{Amp}$ pulse of current was sent across the electrodes (i.e. the cell epithelium) as described earlier (Grima et al. 1998, Lui et al. 2001). In short, Sertoli cells cultured in F12/DMEM were plated on Matrigelcoated bicameral units (in triplicates) at $1.2 \times 10^{6}$ cells $/ \mathrm{cm}^{2}$ at time 0 , and TER was recorded daily, with fresh F12/DMEM replenished after the TER measurement. On day 3 , when the TJ permeability barrier was established as manifested by a stable TER across the Sertoli cell epithelium, transfection was performed to silence either Oatp3 (Slco1a5) alone or in combination with three other drug influx pumps, namely OCTN2 (Slc22a5), TST-1 (Slco6b1) and TST-2 (Slco6c1) using the corresponding siRNA duplexes versus the non-targeting control siRNA duplexes to assess the effects of RNAi on the Sertoli cell TJ permeability barrier function.
A

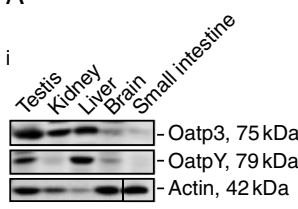

C
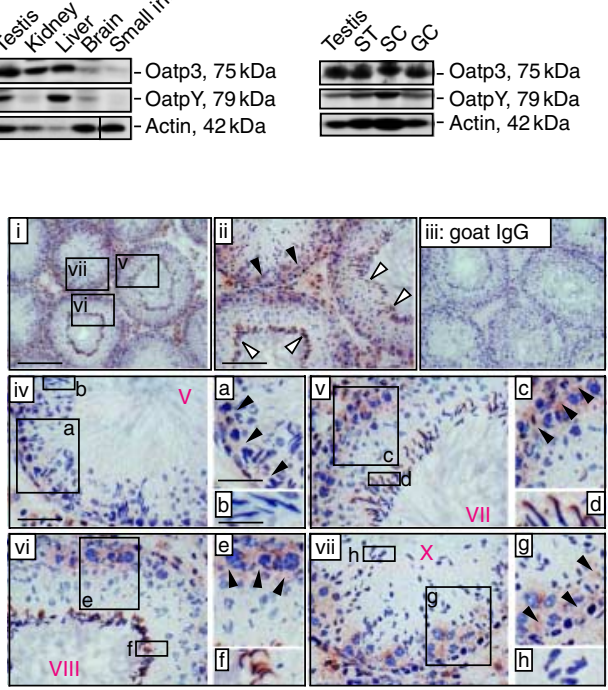

D

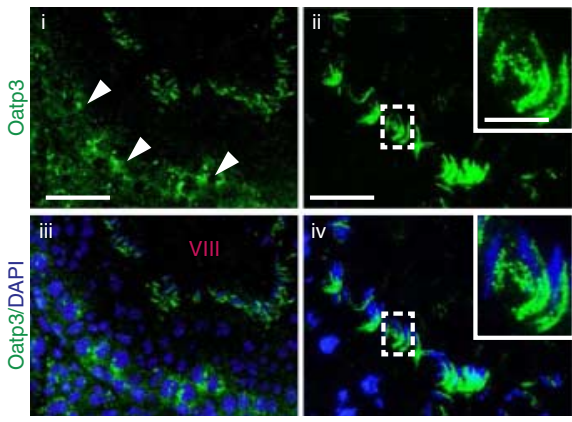

Figure 1 Cellular distribution of Oatp3 in the seminiferous epithelium of adult rat testes. (A) Immunoblot analysis using tissue lysates $(\sim 100 \mu \mathrm{g}$ protein) of testes, kidney, liver, brain, small intestine, seminiferous tubules (ST) (these organs or tissues were all obtained from adult male rats), Sertoli cells (SC; from 20-day-old rats), and germ cells (GC; from adult rats) and a specific anti-Oatp3 or anti-OatpYantibody (see Table 1 ) (A i and ii). Actin served as a protein loading control. (B) An immunoblot illustrating the specificity of the anti-Oatp3 antibody with lysate from testes, which was used for immunohistochemistry (C) and immunofluorescence microscopy (D). (C) Localization of Oatp3 in the seminiferous epithelium by immunohistochemistry using frozen sections of testes and the anti-Oatp3 antibody (Table 1) (see i-ii, iv-vii, with iii as a negative control using normal goat IgG instead of the anti-Oatp3 antibody). Immunoreactive Oatp3 (reddish brown) was detected at the BTB (black arrowheads) in virtually all stages of the epithelial cycle but most prominently (and the highest expression) at stages VII-X. Intensive Oatp3 staining was also found at the apical ES (white arrowheads) in stage VII-VIII tubules, which became relatively weaker at other stages. In C, a-b, $\mathrm{c}-\mathrm{d}$, e-f, and $\mathrm{g}-\mathrm{h}$ are magnified images of the corresponding boxed areas shown in iv, v, vi and vii. V, VII, VIII, X in 'red' refer to stages of tubules. Scale bar, $200 \mu \mathrm{m}$ in C i, which applies to C iii; $100 \mu \mathrm{m}$ in C ii; $50 \mu \mathrm{m}$ in C iv, which applies to v, vi, and vii; $30 \mu \mathrm{m}$ in a, which applies to C, e, and g; $20 \mu \mathrm{m}$ in b, which applies to d, f, and h. (D) Immunofluorescence staining pattern of Oatp3 in rat testes. The stage-specific localization of Oatp3 in the testis shown in i-iv in D, such as at the BTB (white arrowheads in $\mathrm{i}$ ) and the apical ES (see ii and iv) is consistent with findings in C. Insets in $\mathrm{ii}$ and iv are the magnified images of the corresponding boxed areas at the apical ES. iii-iv are the merged images of $\mathrm{i}-\mathrm{ii}$ wherein cell nuclei were stained with DAPI. $50 \mu \mathrm{m}$ in D i, which applies to iii; $20 \mu \mathrm{m}$ in D ii, which applies to iv; $10 \mu \mathrm{m}$ in inset in D ii, which applies to inset in D iv. Full colour version of this figure available via http://dx.doi.org/10.1530/JOE-10-0474. 


\section{$R N A$ extraction and RT-PCR}

As anti-OCTN2, anti-TST-1, and anti-TST-2 antibodies that could be used for immunoblot analysis were not available, we had used RT-PCR to assess the efficacy of their knockdown following RNAi. Total RNAs were extracted from Sertoli cells on day 3 after transfection with siRNA duplexes (see Table 2) using TRIzol reagent (Invitrogen). Contaminating genomic DNA in each RNA sample, if any, was digested with RNase-free DNase I (Invitrogen) prior to their use for reverse transcription into cDNAs using Moloney murine leukemia virus reverse transcriptase (M-MLV RT) reagent (Invitrogen). PCR was performed as described (Lui et al. 2003a, Su et al. 2009) using primer pairs specific to corresponding target genes (Table 3 ) and co-amplified with ribosomal S16, which served as an internal control for equal sample processing and RNA loading.

\section{Quantitative real-time RT-PCR and data analysis}

To further confirm the extent of gene silencing by RNAi as specific and/or working antibodies are not available for some influx pump transporters (e.g. Slc22a5, Slco6b1, and Slco6c1), quantitative real-time RT-PCR (qPCR) was used. qPCR was performed using an Applied Biosystems (Foster City, CA, USA) Prism 7700 Sequence Detection System with SYBR Green PCR Master Mix and primer pairs listed in Table 4. Primers for qPCR were designed using either the Oligonucleotide Properties Calculator at www.basic.northwestern.edu/biotools/oligocalc.html or the Primer Express (Version 2.0) from Applied Biosystems, Inc., and were compared with existing database at GenBank using the basic local alignment search tool (BLAST) to ensure specificity (Table 4). qPCR was performed at the Rockefeller University Genomics Resource Center as described earlier (Xia et al. 2007). Equal amount of total RNA was then reverse transcribed using M-MLV RTwith $2 \mu \mathrm{g}$ RNA in a $25 \mu \mathrm{l}$ reaction. Both primers ( $5 \mathrm{pmol}$ each) and various templates (including serially diluted control testis cDNA for generating the standard curve) and $1 \mu$ reverse transcription product as described above were mixed with $2 \times$ SYBR Green PCR Master Mix in a $25 \mu \mathrm{l}$ final reaction volume. The thermal cycler conditions were $10 \mathrm{~min}$ at $95^{\circ} \mathrm{C}$, followed by two-step (15 s at $95^{\circ} \mathrm{C}$ and $1 \mathrm{~min}$ at $60^{\circ} \mathrm{C}$ ) PCR for 40 cycles, and a slow heating up to $95^{\circ} \mathrm{C}$ for dissociation analysis at the end to ensure the purity of the PCR product. Amplification data analysis was performed using Applied Biosystems SDS 2.3 software as described in detail (Xia et al. 2007).

\section{Statistical analysis}

Statistical analyses were performed by two-way ANOVA with Tukey's honest significant test or Student's t-test using GB-STAT software (Version 7.0, Dynamic Microsystems, Silver Spring, MD, USA) to compare treatment and control groups as described (Yan et al. 2008a). Results of qPCR were analyzed by one-way ANOVA for multiple comparisons using the JMP IN statistical analysis software package (Version 4, SAS, Inc., Cary, NC, USA).

\section{Results}

Stage-specific localization of Oatp3 (Slco1a5) in the seminiferous epithelium of adult rat testes

Oatp3 displayed a broad tissue expression that was detected in testes, kidney, liver, brain and small intestine in adult male rats ( 300 g b.w.) (Fig. 1Ai). In the testis, Oatp3 was found in the seminiferous tubules, Sertoli cells, and germ cells (Fig. 1Aii). The anti-Oatp3 antibody used for the various experiments reported in this study was selected based on the preliminary experiments when three anti-Oatp3 antibodies from different
A

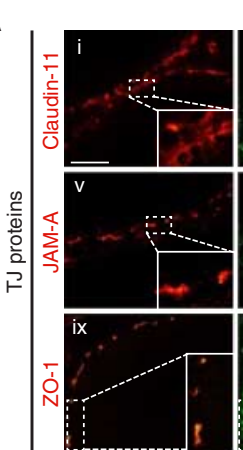

B

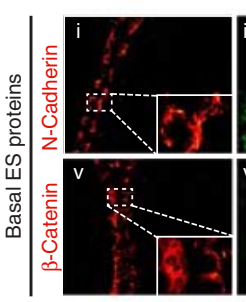

C

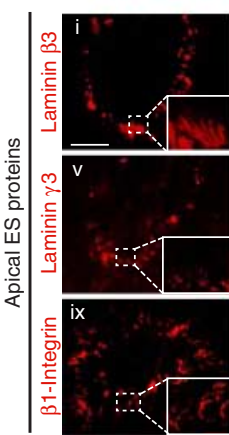

Oatp3
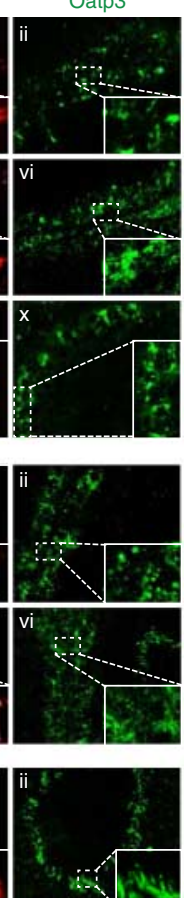

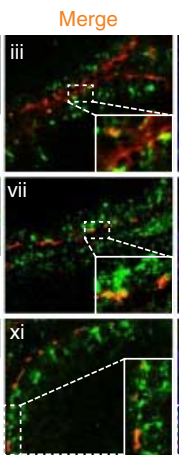

Merge/DAPI
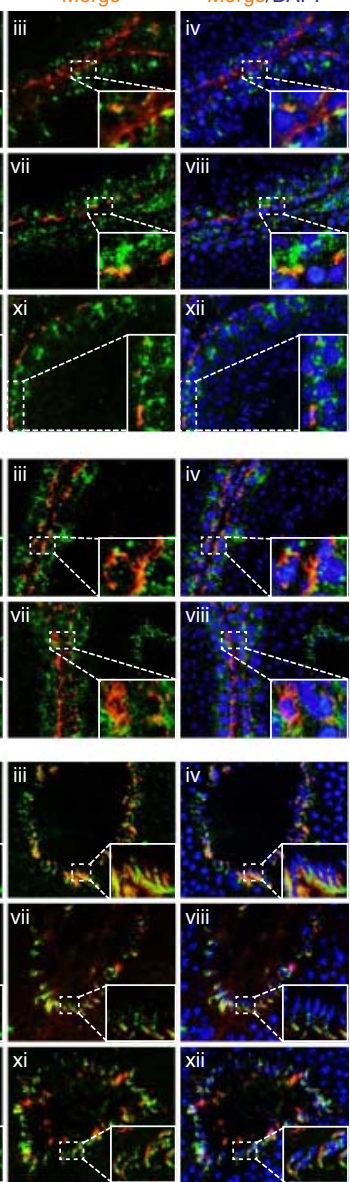

Figure 2 Dual-labeled immunofluorescence analysis on the co-localization of Oatp3 with putative BTB and apical ES proteins in the seminiferous epithelium. (A) Partial co-localization (see orange color) of Oatp3 with TJ proteins: claudin-11 (i-iv), JAM-A (v-viii), and ZO-1 (ix-xii) at the BTB. (B) Partial co-localization of Oatp3 with basal ES proteins: $\mathrm{N}$-cadherin (i-iv) and $\beta$-catenin $(v-v i i i)$ at the BTB. (C) Co-localization of Oatp3 with apical ES proteins: laminin $\beta 3$ (i-iv), laminin $\gamma 3$ ( $v$-viii), and $\beta 1$-integrin (ix-xii). Insets are magnified images of the corresponding boxed areas in the same micrographs. Scale bar: $50 \mu \mathrm{m}$ in Ai, which applies to all images in $B$ and $C ; 15 \mu \mathrm{m}$ in inset in $\mathrm{Ai}$, which applies to all insets in $A, B$, and $C$. Full colour version of this figure available via http://dx.doi.org/10.1530/JOE-10-0474. 
vendors were compared, and its specificity was illustrated by immunoblot analysis (Fig. 1B and Table 1). Although this antibody yielded some faint staining for some unwanted proteins, it was the best antibody based on the initial pilot experiments (and at the selected dilution, the staining was shown to be specific based on pilot experiments using different dilutions) and appropriate dilutions were thus selected for different applications as noted in Table 1. Immunoreactive Oatp3 was detected near the basement membrane consistent with its localization at the BTB in almost all stages of the epithelial cycle, being highest at stages VII-X (Fig. 1C), at the time of BTB restructuring to facilitate the transit of preleptotene spermatocytes. Considerably weaker staining was detected at the BTB at stages III-V. Oatp3 staining was intense at the apical ES at stages VII-VIII, coinciding with spermiation that occurs at stage VIII of the epithelial cycle. Fluorescence microscopy also confirmed Oatp 3 localization at the BTB and apical ES (Fig. 1D). Some Oatp3 staining was also found in the interstitial cells, associated with Leydig cells.

\section{Co-localization of Oatp3 with junction proteins at the BTB and apical ES}

Dual-labeled IF analysis was used to examine protein co-localization. At the BTB, Oatp3 displayed partial co-localization with TJ- (e.g. claudin-11, JAM-A, and ZO-1; Fig. 2A) and basal ES-proteins (e.g. N-cadherin and $\beta$-catenin; Fig. 2B). At the apical ES, Oatp3 almost superimposed with putative apical ES proteins: laminin $\beta 3$, laminin $\gamma 3$, and $\beta 1$-integrin (Fig. 2C).

\section{Changes in the expression and localization of Oatp 3 during adjudin-induced germ cell loss in the testes}

Adjudin $\left(\mathrm{C}_{15} \mathrm{H}_{12} \mathrm{Cl}_{2} \mathrm{~N}_{4} \mathrm{O}\right.$, Mr 335-18), a potential male contraceptive, is known to induce germ cell loss from the seminiferous epithelium by perturbing, most notably, apical ES (Mruk et al. 2008). In adult rats treated with adjudin, the increase in Oatp 3 was noted at $3 \mathrm{~h}$ after adjudin administration (Fig. 3Ai-ii). This increase maintained for $\sim 1$ day but declined rapidly and was significantly lower by day 4 , suggesting that testis 'shut-off' the influx pump to prevent entry of adjudin (note: adjudin is a toxicant for spermatogenesis) into the apical compartment by reducing the expression of Oatp3. As adjudin induced testis weight loss (Fig. 3Aiii) because of germ cell depletion from the seminiferous epithelium and the cellular composition in the samples being analyzed for Oatp3 and OatpY and shown in Fig. 3A:ii did not account for these changes, the data in Fig. 3A:ii were corrected for testis weight changes and shown in Fig. 3A:iv, illustrating a transient increase in Oatp3 expression indeed occurred and it was reduced by days $2-4$ but not OatpY. Changes in the localization of Oatp3 in the seminiferous epithelium during adjudin-induced germ cell loss were also examined (Fig. 3B). Oatp3 was detected at both BTB and the apical ES in normal stage VIII tubules (Fig. 3Bi, a negative control shown in Fig. $3 \mathrm{Bv}$ ) similar to findings shown in Fig. 1C. A stage V-VI tubule was found to have adjudininduced misaligned spermatids $12 \mathrm{~h}$ after drug administration with intense Oatp3 staining at the apical ES (Fig. 3Bii), which was not seen in a normal stage V-VII tubule (see Fig. 1). When these spermatids are depleting from the epithelium, considerably more Oatp3 was found that surrounded these

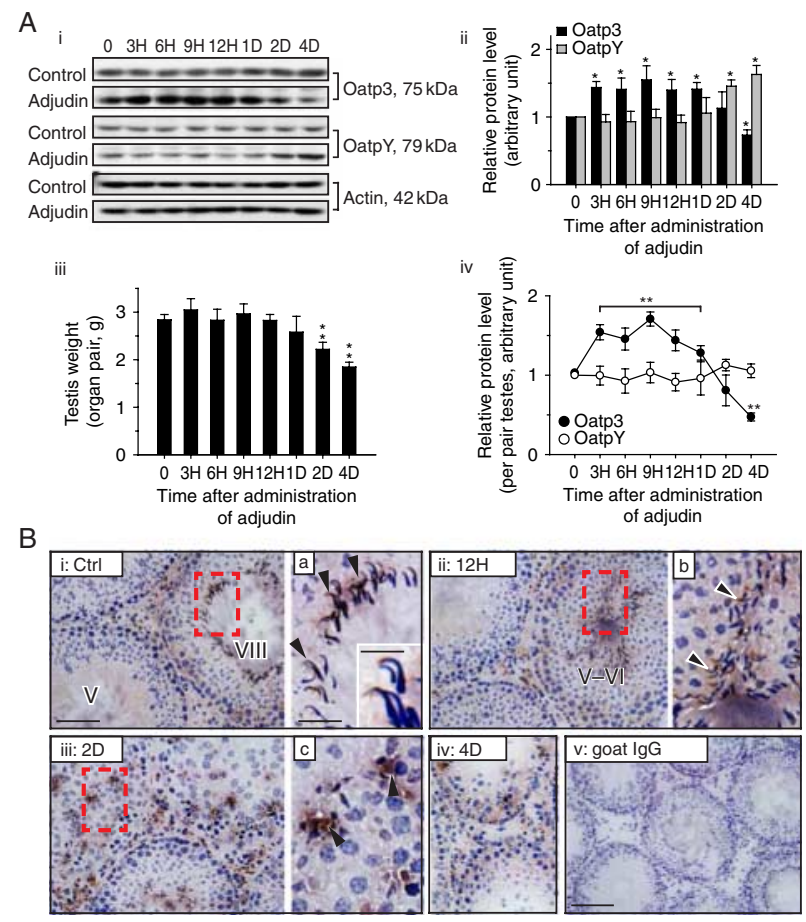

Figure 3 Changes in the steady-state levels and/or cellular distribution of Oatp3 versus OatpY during adjudin-induced anchoring junction restructuring in the seminiferous epithelium that leads to germ cell loss from the testis. (A) Representative immunoblotting results illustrating changes in steady-state levels of Oatp3 and OatpY in the testis after adjudin treatment (single dose at $50 \mathrm{mg} / \mathrm{kg}$ b.w., by gavage) administered to adult rats ( $\sim 300 \mathrm{~g} \mathrm{b.w.)}$ at time $0(\mathrm{~A}$ i). Composite immunoblot results ( $n=3-5$ rats) such as those shown in i normalized against actin, wherein the elative protein level at time 0 in $(\mathrm{A}$ i) was arbitrarily set at 1 , against which statistical analysis was performed ( $\mathrm{A}$ ii). Bar graphs showing changes of testis weight during development and after adjudin treatment (A iii). Line graphs showing composite protein level changes of Oatp3 versus OatpY per pair testes (A iv). Each bar is the mean \pm s.D. of $n=3-5$ rats. ${ }^{*} P<0 \cdot 05 ;{ }^{*} P<0 \cdot 01$ by ANOVA. (B) Frozen sections of testes from normal (B i) and adjudin-treated (B ii-iv) adult rats were immunostained with anti-Oatp3 antibody. Oatp3 staining was detected at the Sertoli-elongated spermatid interface (black arrowheads) at the apical ES in control (B i) and $12 \mathrm{H}$ after (B ii) adjudin treatment and also at the Sertoli-round spermatid interface (black arrowheads) at the desmosome-like junction in $2 \mathrm{D}$ (B iii) and 4 D (B iv) after adjudin treatment. (B v) Negative control in which normal goat IgG was used to substitute the anti-Oatp3 antibody. $\mathrm{B}$ a-C are the magnified images of the corresponding boxed areas in $\mathrm{B}$ $\mathrm{i}-\mathrm{iii}$. Inset in $\mathrm{B}$ a is a further enlarged area to illustrate the localization of Oatp3 at the apical ES. Scale bar: $100 \mu \mathrm{m}$ in B i, which applies to ii-iv; $200 \mu \mathrm{m}$ in B v; $50 \mu \mathrm{m}$ in a, which applies to b, c; $15 \mu \mathrm{m}$ in inset in a. Full colour version of this figure available via http://dx.doi.org/10. 1530/JOE-10-0474. 
cells, including the Sertoli cell-round spermatid interface (Fig. 3Biii-iv), seemingly suggesting that this influx pump might have allowed more adjudin to reach these misaligned spermatids to cause their defoliation.

\section{Does Oatp3, an integrated component of adhesion protein} complexes at the BTB, regulate drug entry to the testis?

Oatp3 was shown to structurally associate with components of adhesion protein complexes at the BTB including basal ES proteins $\mathrm{N}$-cadherin, $\beta$-catenin, $\mathrm{ZO}-1$, and actin, but not TJ-proteins occludin, FAK, and c-Src by Co-IP (Fig. 4A).
This finding was further confirmed by dual-labeled IF analysis illustrating the co-localization of Oatp3 with ZO-1, $\mathrm{N}$-cadherin, and $\beta$-catenin at the Sertoli-Sertoli cell interface (Fig. 4B). To further explore the role of Oatp3 in drug entry to the testis, Sertoli cells cultured for 3 days with an established TJ barrier was incubated with adjudin at $1 \mu \mathrm{g} / \mathrm{ml}$ for various time points (Fig. 4C). After adjudin treatment, the steady-state level of Oatp3 was upregulated by 1.5-fold from days 1-3 (Fig. 4C) and its staining intensity at Sertoli-Sertoli interface was also induced versus control (Fig. 4D). An increase in association between Oatp 3 and $\mathrm{ZO}-1, \beta$-catenin, or actin after adjudin treatment was also detected (Fig. 4E), suggesting that more
A

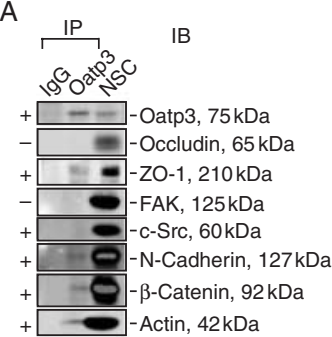

D

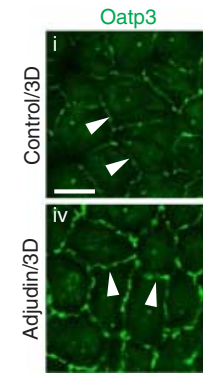

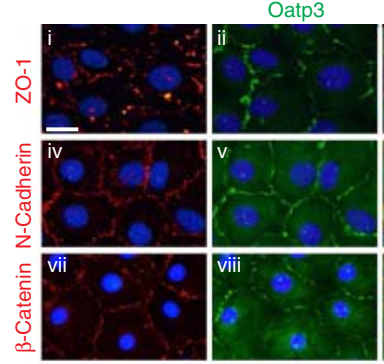

$\mathrm{E}$ Oatp3/DAPI
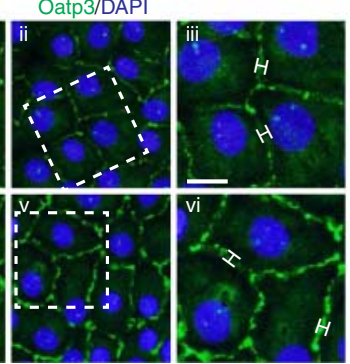

Merge
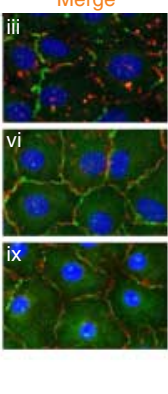
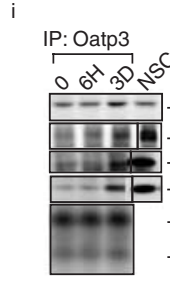

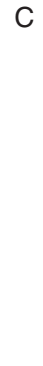

\section{i}

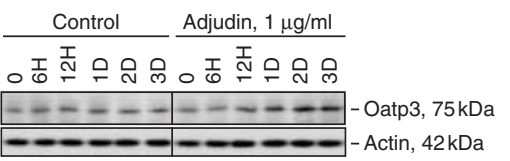

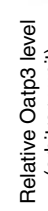

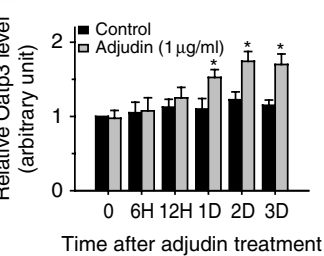

IB:

ii

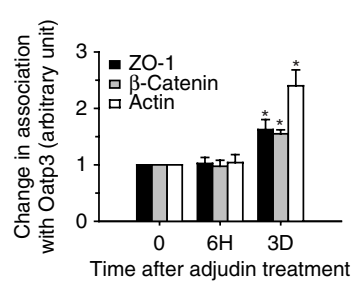

Figure 4 A study to examine the binding partners of Oatp3 and changes in protein-protein interactions at the BTB in Sertoli cell epithelium in vitro following treatment with adjudin. (A) Co-IP was performed using lysates ( $200 \mu \mathrm{g}$ protein) from Sertoli cells $\left(0.5 \times 10^{6} \mathrm{cell} / \mathrm{s} / \mathrm{cm}^{2}\right.$ cultured alone for 4 days on Matrigel-coated dishes, forming an intact cell epithelium and the presence of a functional TJ permeability barrier, see Fig. 5, with ultrastructures of TJ, basal ES, and desmosome-like junction when examined by electron microscopy (Siu et al. 2005) that mimicked the Sertoli cell BTB in vivo), Oatp3 was shown to structurally interact with ZO-1, $\mathrm{N}$-cadherin, $\beta$-catenin, and actin (indicated by ' $+{ }^{\prime}$ ), but not occludin, FAK, or c-Src (indicated by ' $-{ }^{\prime}$ ). Sertoli cell lysates Co-IP with normal goat IgG (IgG) and Sertoli cell lysates alone without Co-IP (NSC) served as the corresponding negative and positive control. This experiment was repeated three times using different batches of Sertoli cell cultures that yielded similar results. (B) Dual-labeled immunofluorescence analysis illustrating co-localization of Oatp3 with ZO-1, N-cadherin, and $\beta$-catenin at the Sertoli-Sertoli cell interface. Scale bar: $15 \mu \mathrm{m}$ in i, which applies to ii-ix. (C) Immunoblot (top panel) using Sertoli cell lysates wherein cells were treated with adjudin $(1 \mu \mathrm{g} / \mathrm{ml})$ on day 4 after an intact cell epithelium had been formed for specified time points to assess change in the steady-state level of Oatp3 (C i). Actin blot (lower panel) served as a loading control. These findings were summarized in a bar graph illustrating an upregulation of Sertoli cell Oatp3 expression induced by adjudin from day 1 through 3 post-treatment (C ii). Relative Oatp3 level at time 0 in control group was arbitrarily set as 1 , against which statistical analysis was performed. Each bar is the mean \pm s.D. of $n=4$ using different batches of Sertoli cells. ${ }^{*} P<0 \cdot 05$ by ANOVA. (D) Immunofluorescence microscopy (see i-vi) was used to verify data shown in (C) illustrating a brighter and broader staining pattern of Oatp3 (see bars in iii versus vi) at the Sertoli-Sertoli cell interface (white arrowheads in $\mathrm{i}$ and iv) by 3 days after adjudin treatment. iii and vi are enlarged images of the corresponding boxed areas in D ii and v. Nuclei were stained with DAPI. Scale bar: $15 \mu \mathrm{m}$ in i, which applies to ii, iv, and v; $7 \mu \mathrm{m}$ in iii, which applies to vi. (E) Co-IP to assess changes in association of Oatp3 with ZO-1, $\beta$-catenin, or actin following adjudin treatment using $\sim 300 \mu$ g protein lysate per sample tube (E i). Normal Sertoli cell lysate without Co-IP was used as positive control (NSC). The bottom panel is the IgGH and IgGL chains, illustrating equal protein loading in this Co-IP experiment and that there was indeed an increase in association between ZO-1, $\beta$-catenin, and actin with Oatp3 during adjudin-induced anchoring junction restructuring in the epithelium. Densitometric analyses of blots such as those shown in ( $\mathrm{E} i)$, illustrating an increase in association between these proteins (E ii). Relative association of the target protein with Oatp3 at time 0 was arbitrarily set as 1 . Each bar is the mean \pm s.D. of $n=3$. ${ }^{*} P<0.05$ by ANOVA. Full colour version of this figure available via http://dx.doi.org/10.1530/JOE-10-0474. 
Oatp3 was 'recruited' to the BTB site to facilitate drug entry to the seminiferous epithelium. We next investigated whether the effects of influx pump to regulate drug entry would impede the Sertoli cell TJ permeability barrier function.

The influx pump function of Oatp3 appears to operate independent of the TJ permeability barrier function

As Oatp3 is an integrated component of the N-cadherinbased adhesion protein complex at the BTB, we sought to examine whether Oatp3 knockdown would impede the Sertoli cell TJ barrier function (Fig. 5A-G). On day 3 after Sertoli cells established a function TJ barrier (Fig. 5G), cells were transfected with the specific Oatp3 siRNA duplexes versus the non-targeting control siRNA duplexes. While a $\sim 60 \%$ knockdown of Oatp3 was noted (Fig. 5A and B) with the concomitant disappearance of Oatp3 from the cell-cell interface (Fig. 5C) without off-target effects as far as we examined (Fig. 5A and E; for instance, P-glycoprotein and mrp1, both are efflux pumps, was not affected, similar to other BTB proteins), the Sertoli cell TJ barrier was not perturbed (Fig. 5D, F and G).

Quadruple knockdown of MIDTs by RNAi does not affect the Sertoli cell TJ permeability function

To further validate the concept that the drug transport function at the BTB mediated by influx pumps may be segregated from the TJ barrier function even though drug transporters physically interact with adhesion protein complexes at the BTB, we sought to perform quadruple knockdown of several influx drug pumps in Sertoli cell epithelium and to assess the TJ barrier integrity. Based on the two earlier studies (Augustine et al. 2005, Su et al. 2009), besides Oatp3 (Slco1a5), Slc22a5, Slco6b1, and Slco6c1 are the major influx drug pumps in Sertoli cells, thus these four drug transporters (MIDTs) were selected for the subsequent experiments. When these four influx pumps were

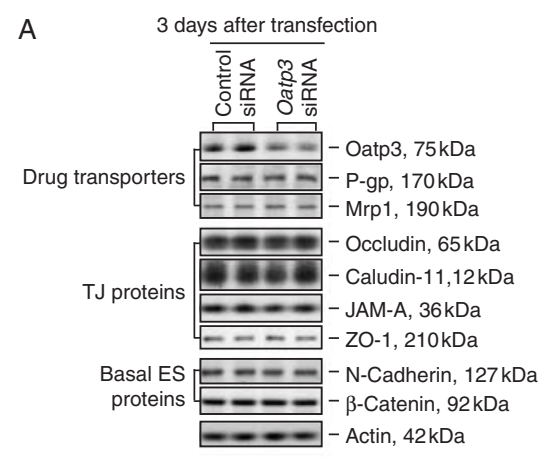

B
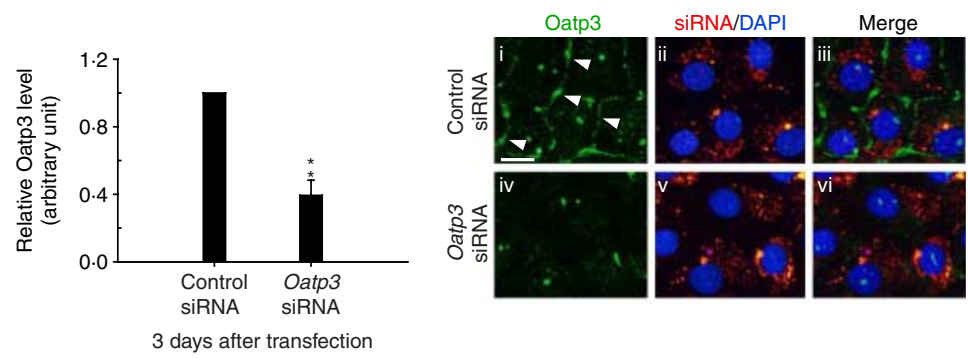

D

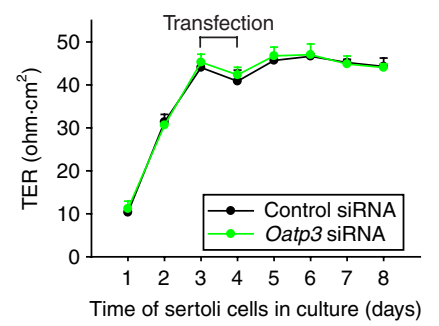

E P-glycoprotein
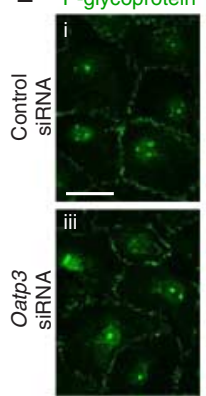
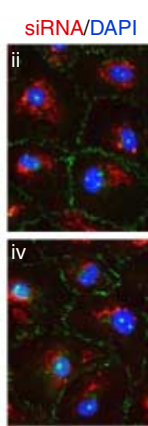

$\mathrm{F}$

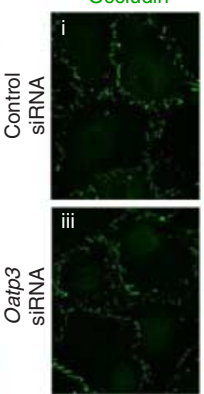

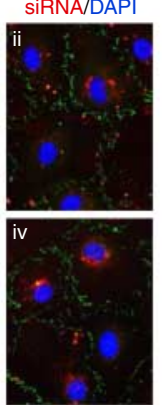
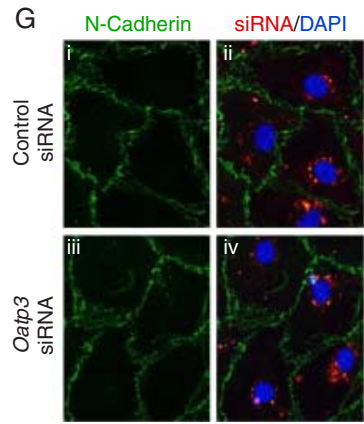

Figure 5 A study to assess any changes on the Sertoli cell BTB function and protein distribution following the knockdown of Oatp3 by RNAi. (A) Sertoli cells cultured at $0 \cdot 5 \times 10^{6}$ cells $/ \mathrm{cm}^{2}$ on Matrigel-coated dishes on day 3 with an established intact cell epithelium were transfected with $100 \mathrm{nM}$ Oatp3-specific siRNA duplexes versus non-targeting control duplexes, cells were harvested 3 days thereafter. (B) Although a $\approx 60 \%$ decline in the steady-state protein level of Oatp3 was noted, no changes in two major efflux drug transporters, P-glycoprotein (P-gp) and Mrp1, or other TJ and basal ES junction proteins were detected illustrating no off-target effects (A). ${ }^{* *} P<0 \cdot 01$ by Student's $t$-test. (C) Sertoli cells cultured at $0 \cdot 05 \times 10^{6}$ cells $/ \mathrm{cm}^{2}$ for 3 days were transfected with CY3-labeled Oatp3specific siRNA duplexes (red) and non-targeting control duplexes (red) for $24 \mathrm{~h}$ and were staining with anti-Oatp3 antibody (green). Much of the immunoreactive Oatp3 at the Sertoli-Sertoli cell interface (arrowheads) was diminished considerably after RNAi when compared with controls (iv-vi versus i-iii). (D) The Sertoli cell TJ permeability barrier function was also monitored by quantifying transepithelial electrical resistance (TER) across the cell epithelium after Oatp3 RNAi versus controls, illustrating no effect of Oatp3 knockdown on Sertoli cell TJ barrier function. (E-G) Oatp3 knockdown did not affect the distribution of P-glycoprotein (E iii-vi versus $\mathrm{i}-\mathrm{ii}$ ), occludin ( $\mathrm{F}$ iii-vi versus $\mathrm{i}-\mathrm{ii}$ ) or $\mathrm{N}$-cadherin (G iii-vi versus $\mathrm{i}-\mathrm{ii})$ at the Sertoli-Sertoli cell interface. Scale bar, $15 \mu \mathrm{m}$ in $\mathrm{C}$ i, which applies to ii-vi; $30 \mu \mathrm{m}$ in E i, which applies to ii-iv and also i-iv in both F and G. Full colour version of this figure available via http://dx. doi.org/10.1530/JOE-10-0474. 
A
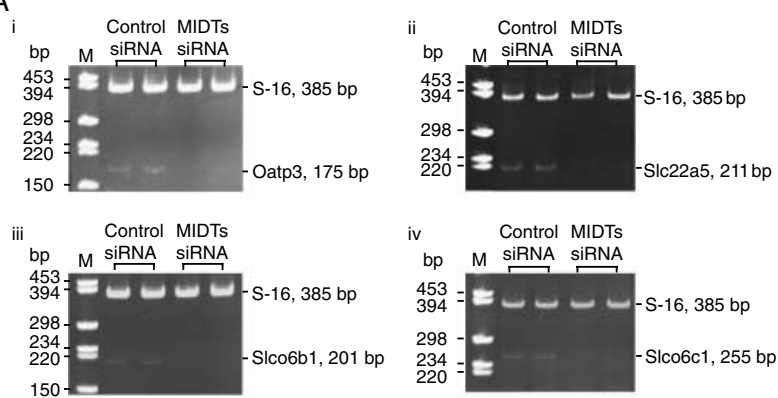

B

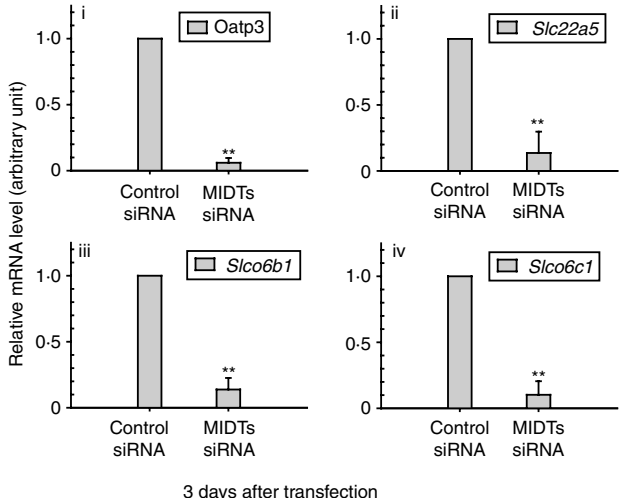

$\mathrm{C}$

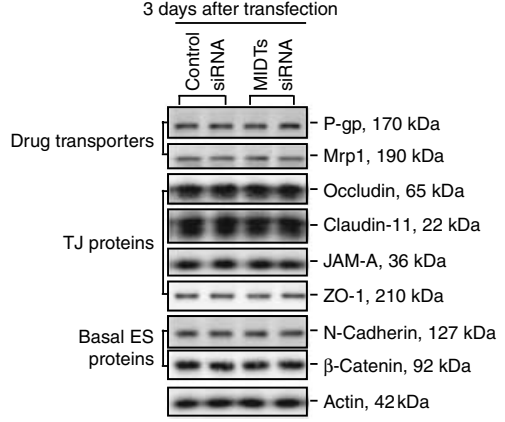

Figure 6 A study to assess the efficacy of simultaneous knockdown of multiple influx drug transporters (MIDTs): Oatp3 (S/co1a5), Slc22a5, Slco6b1, and Slco6c1 by RNAi without off-target effects. (A) Sertoli cells isolated from 20-day-old rat testes were plated at time 0 and cultured at $0.5 \times 10^{6} \mathrm{cell} / \mathrm{s} / \mathrm{cm}^{2}$ to allow the establishment of a functional TJ barrier. On day 3, these cultures were transfected with $200 \mathrm{nM}$ MIDT (50 nM each)-specific siRNA duplexes versus non-targeting control siRNA duplexes for $24 \mathrm{~h}$, and cells were terminated for RNA extraction 3 days thereafter to assess silencing efficacy. RT-PCR illustrated that the quadruple knockdown of Oatp3 (i), Slc22a5 (ii), Slco6b1 (iii), and Slco6c1 (iv) reduced the corresponding steady-state mRNA level by $\sim 70-80 \%$ for each target gene with S-16 served as an internal control. (B) The findings in (A) were validated by qPCR shown in (i)-(iv) for the corresponding target influx pump transporters with an $\sim 70-80 \%$ knockdown. ${ }^{* *} P<0 \cdot 01$ by ANOVA. (C) Immunoblot analysis showed that there was no off-target effect following the knockdown of MIDTs as multiple proteins including P-glycoprotein (P-gp, an efflux pump) and multidrug resistance-associated protein 1 (Mrp1) were not affected, illustrating that the silencing is specific to the corresponding target drug transporter. knockeddown by RNAi using corresponding siRNA duplexes versus control duplexes with $\sim 70-80 \%$ efficacy (up to $>95 \%$ efficacy in some cases) when verified by RT-PCR and qPCR (Fig. 6A and B), no off-target effects were detected (Fig. 6C), illustrating the specificity of the RNAi experiments. Consistent with results shown in Fig. 5, the quadruple knockdown of MIDTs did not perturb the Sertoli cell TJ barrier function (Fig. 7A) nor the distribution of occludin or N-cadherin at the Sertoli-Sertoli cell interface (Fig. 7B), confirming that the TJ barrier integrity was not compromised.

A knockdown of Oatp3 or MIDTs by RNAi impedes the transit of $\left.{ }^{3} H\right]$ adjudin at the BTB in Sertoli cell epithelium

The entry of drugs, such as adjudin, into the microenvironment, namely the apical compartment, behind the BTB in the testis remains unknown (Mruk \& Cheng 2008) when receptors are not present in Sertoli cells. For instance, adjudin has exceedingly poor bioavailability (Cheng et al. 2005), possibly due to the lack of a specific a receptor. In this study, we tested the hypothesis that drug entry into the testis is mediated by drug transporters by RNAi. On day 3, Sertoli cells having an established TJ barrier were transfected with corresponding siRNA duplexes to knockdown either Oatp3 alone or MIDTs, and 3 days thereafter when these genes were silenced (see Fig. 6A-C), $\left[{ }^{3} \mathrm{H}\right]$ adjudin was added to the basal compartment of the bicameral units at time 0 . At specified time points as shown in Fig. $7 \mathrm{C}$, an aliquot of $50 \mu \mathrm{l}$ medium was withdrawn from the apical and basal compartment for radioactivity determination to quantify the movement of $\left[{ }^{3} \mathrm{H}\right]$ adjudin across the Sertoli cell BTB when the TJ barrier was not compromised (Fig. 7A and B, Fig. 5D). A knockdown of Oatp3 alone impeded the transport of $\left[{ }^{3} \mathrm{H}\right]$ adjudin across the Sertoli cell TJ barrier, but the quadruple knockdown of MIDTs impeded $\left[{ }^{3} \mathrm{H}\right]$ adjudin considerably more effectively than Oatp3 knockdown alone (Fig. 7C). These findings illustrate that drug entry in the testis is mediated by influx drug pumps. Although Oatp3 is an integrated component of protein complexes that confer $\mathrm{TJ}$ barrier function at the BTB, drug entry into the epithelium behind the BTB is not mediated by a 'disruption' of the TJ barrier. Instead, it is mediated by a drug transport mechanism, involving at least influx pumps, independent of the TJ permeability barrier function.

\section{Discussion}

Does Oatp3, an influx pump and an integrated component of the $N$-cadherin-based adhesion protein complex, regulate the Sertoli cell TJ permeability barrier function?

ATP-binding cassette transporters, such as P-glycoprotein (a multidrug resistance protein) and breast cancer resistance protein that are expressed by Sertoli cells, peritubular myoid 
cells, and germ cells (most notably late spermatids) in the testis (for a review, see Setchell (2008)), are efflux pumps that actively transport drugs 'out' of epithelial or endothelial cells, or 'prevent' drugs from entering cells, utilizing a primary active transport mechanism utilizing ATP (Dallas et al. 2006, Miller et al. 2008, Shen \& Zhang 2010). Unlike these efflux pump transporters, influx pumps, such as SLC transporters, including Oatp3, OCTN2 (Slc22a5), TST-1 (Slco6b1), and TST-2 (Slco6c1) that were examined in this report, that transport drugs 'into' epithelial or endothelial cells utilize one of the two non-ATP-dependent mechanisms (El-Sheikh et al. 2008, Kis et al. 2010, Ueno et al. 2010). First, the energy that pumps drugs or small molecules into cells via an influx pump derives from a gradient that is created by a primary active transport system such as the electrochemical potential difference created by pumping ions (e.g. $\mathrm{Na}^{+}$and $\mathrm{K}^{+}$). Secondly, drugs, ionic compounds, or heavy metals enter cells via the 'pores' in SLC transporters. Since Oatp3 is an integrated component of the $\mathrm{N}$-cadherin-based cell adhesion protein complex at the BTB that structurally interacts with $\mathrm{N}$-cadherin, $\beta$-catenin, and ZO-1, but not occludin or FAK (note: FAK forms a regulatory protein complex with occludin at the BTB (Siu et al. 2009b)) as reported in this study, we speculated that these influx pumps might mediate their effects to transport drugs across the Sertoli cell BTB via changes in the TJ permeability barrier. In fact, the protein-protein
A

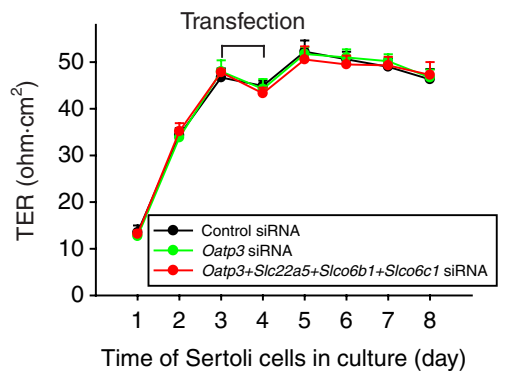

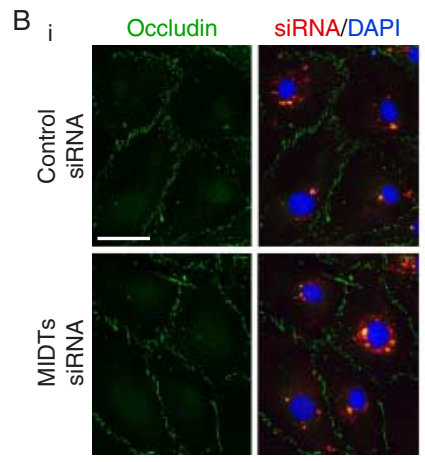

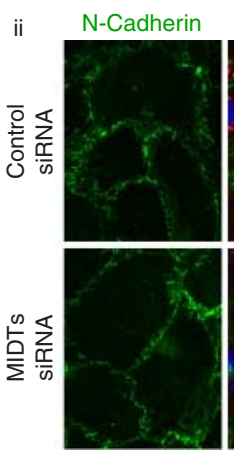

SiRNA/DAPI

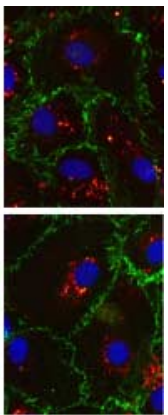

C

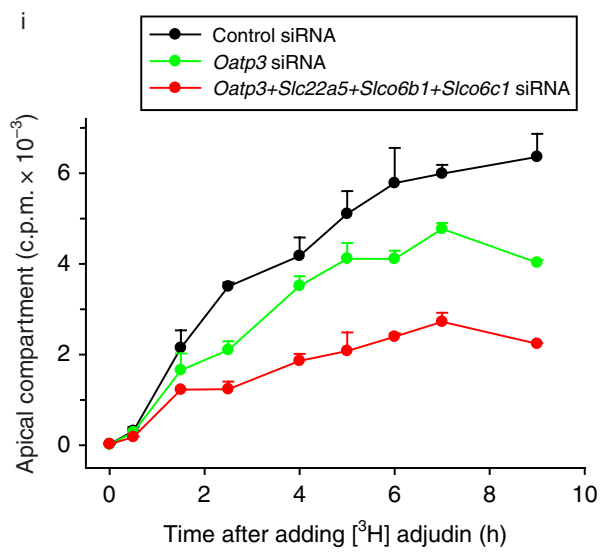

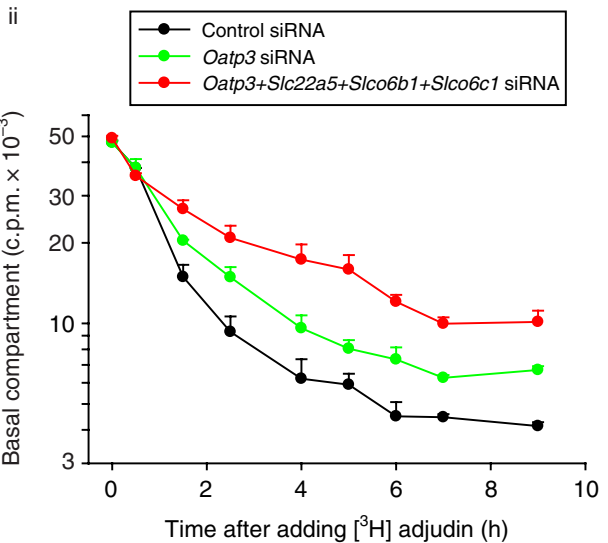

Figure 7 A study to assess the effects of simultaneous knockdown of multiple influx drug transporters (MIDTs): Oatp3 (S/co1a5), S/c22a5, Slco6b1, and S/co6c1 by RNAi on the Sertoli cell TJ permeability function as well as the ability of drug transport across the BTB assessed by $\left[{ }^{3} \mathrm{H}\right]$ adjudin entry from the basal to the apical compartment. (A) The silencing of Oatp3 alone (50 nM Oatp3 siRNA + $150 \mathrm{nM}$ control siRNA) or all four drug influx pumps ( $50 \mathrm{nM}$ for each drug transporter to a total of $200 \mathrm{nM}$ siRNA duplexes) versus non-targeting control siRNA duplexes $(200 \mathrm{nM})$ failed to perturb the Sertoli cell TJ barrier function when TER across the cell epithelium was monitored. (B) Dual-labeled immunofluorescence analysis illustrated that there were no changes in the distribution of occludin (i) or N-cadherin (ii) at the Sertoli-Sertoli cell interface after MIDTs knockdown. Scale bar, $30 \mu \mathrm{m}$ in D i, which applies to remaining micrographs in both D i and ii. (C) A study to assess the effects of Oatp3 knockdown or quadruple MIDTs knockdown by RNAi on the transport of $\left[{ }^{3} \mathrm{H}\right]$ adjudin cross the Sertoli cell epithelium. Sertoli cells were cultured alone on Matrigel-coated bicameral units at $1 \cdot 2 \times 10^{6} \mathrm{cells} / \mathrm{cm}^{2}$ for 3 days, forming an intact cell epithelium, and thereafter, cells were transfected with non-targeting control, Oatp3-specific, or MIDTs siRNA duplexes for 24 h. After 2 days (i.e. 3 days after initial transfection) when targeted drug transporters: Oatp3 alone or Oatp3, Slc22a5, Slco6b1, and Slco6c1 were being knockeddown (see C: i), $\left[^{3} \mathrm{H}\right]$ adjudin $\left(\sim 0.6 \times 10^{6}\right.$ c.p.m.) was added to the basal compartment of the bicameral units and this time was designated time 0 . At selected time points from 0 to $9 \mathrm{~h}, 50 \mu \mathrm{l}$ F12/DMEM was withdrawn from apical (C: i, linear scale) or basal (C: ii, common log scale) compartments (note: each compartment contained $500 \mu \mathrm{l} \mathrm{F12/DMEM)} \mathrm{of} \mathrm{the} \mathrm{bicameral} \mathrm{units} \mathrm{for} \mathrm{radioactivity} \mathrm{determination} \mathrm{in} \mathrm{the} \mathrm{presence}$ of scintillation fluid using a $\beta$-counter. Each data point contains triplicate determinations from both control and experiment groups, and this experiment was repeated three times using different batches of Sertoli cell cultures. Full colour version of this figure available via http://dx.doi. org/10.1530/JOE-10-0474. 
interaction between Oatp3 and ZO-1 or $\beta$-catenin was significantly induced following adjudin treatment, plausibly being used to reinforce the BTB integrity to prevent the entry of adjudin into the apical compartment of the epithelium where post-meiotic spermatid development takes place because adjudin is 'viewed' as a toxicant in relation to spermatogenesis. Furthermore, a recent study has shown that P-glycoprotein is also an integrated component of the occludin-, claudin-11-, and JAM A-based adhesion protein complexes at the BTB (Su et al. 2009). Collectively, these findings thus support the postulate that the presence of drug transporters at the BTB may facilitate or be involved in the maintenance of the Sertoli cell TJ permeability barrier. Surprisingly, a knockdown of Oatp3 alone or a combination of Oatp3 and three other SLC transporters, namely OCTN2 (Slc22a5), TST-1 (Slco6b1), and TST-2 (Slco6c1) did not perturb the Sertoli cell TJ barrier nor protein distribution at the Sertoli-Sertoli cell interface (e.g. occludin and $\mathrm{N}$-cadherin) even though the amount of immunoreactive Oatp3 at the cell-cell interface significantly subsided as a result of the knockdown by RNAi. These findings thus demonstrate unequivocally that even though Oatp3, a SLC transporter and an influx pump, is an integrated component of the adhesion complexes at the BTB, its knockdown does not impede the Sertoli cell TJ barrier function, making it unlikely that drugs can traverse the BTB via an alteration in the TJ barrier function induced by changes in protein-protein interactions between influx pumps and cell adhesion proteins at the site. In this context, it is noted that the Sertoli cell in vitro system to study BTB function is widely used in the field (Janecki et al. 1991b, 1992) and numerous findings obtained based on this in vitro system (Lui et al. 2003a, Siu et al. 2003) have been reproduced in studies in vivo using a BTB integrity assay (Lui et al. 2003b, Li et al. 2006, Xia et al. 2009). In short, this is a reliable system to study Sertoli cell BTB dynamics.

Transport of drug (e.g. adjudin) across the BTB is mediated almost exclusively by influx pumps instead of paracellular transport through the TJ barrier

In an earlier study examining the distribution and organ uptake of $\left[{ }^{3} \mathrm{H}\right]$ adjudin in the testis versus other organs (such as liver, kidney, brain, and small intestine) to assess its bioavailability, it was shown that this drug distributed almost evenly amongst all organs examined with $<0 \cdot 05 \%$ of the total administered reaching the testis and $>95 \%$ being cleared from host animals within 24-48 h (Cheng et al. 2005). Even though the BTB poses an excellent barrier to adjudin, this compound (at $50 \mathrm{mg} / \mathrm{kg}$ b.w., by gavage) limits its effects almost exclusively in the testis by disrupting the testis-specific anchoring junction namely apical ES at the Sertoli-spermatid interface because at up to $2000 \mathrm{~m} / \mathrm{kg}$ b.w. in rats or $1000 \mathrm{mg} /$ $\mathrm{kg}$ b.w. in mice (Ames test), no damage was seen in other organs when performed by licensed toxicologists and results from serum microchemistry also illustrated no associated liver or kidney damage was detected (Mruk et al. 2006, Mruk \& Cheng 2008). Because of the knockdown of either Oatp3 alone or in combination with three other Sertoli cell major SLC influx transporters failed to alter the TJ permeability barrier as reported in this study, these findings suggest that drug transport across the BTB may not be mediated via a transiently 'disrupted' BTB. Instead, the findings reported in this study illustrate that the entry of $\left[{ }^{3} \mathrm{H}\right]$ adjudin across the Sertoli cell BTB into the apical compartment of the bicameral units was significantly impeded when the expression of Oatp3 was knockeddown by RNAi using specific Oatp3 siRNA duplexes, and the quadruple knockdown of four SLC transporters further impeded the transport of $\left[{ }^{3} \mathrm{H}\right]$ adjudin across the Sertoli cell BTB. Thus, drug entry at the BTB is likely mediated via the 'pores' located in the influx pumps instead of a transiently 'disrupted' Sertoli cell TJ barrier. This information is extremely helpful in male contraceptive development, in particular, using compounds (e.g. adjudin) that likely exert their effects in the apical compartment of the seminiferous epithelium behind the BTB. In this context, it is of interest to note that $\sim 10 \%$ of $\left[{ }^{3} \mathrm{H}\right]$ adjudin added onto the basal compartment of the bicameral unit could reach the apical compartment. However, earlier studies to assess the bioavailability of $\left[{ }^{3} \mathrm{H}\right]$ adjudin by administering this compound to adult rats orally and to assess its recovery in the testis illustrates that fewer than $\sim 1 \%$ could reach the seminiferous epithelium (Cheng et al. 2005), and this extremely low bioavailability is consistent with studies of pharmacokinetics to assess its tissue distribution in both rats (Mruk et al. 2006) and rabbits (Hu et al. 2009). This is likely due to the lack of myoid cell layer in the in vitro system because the myoid cell layer surrounding the seminiferous tubule is known to significantly contribute to the BTB function in rodents (Dym \& Fawcett 1970, Fawcett et al. 1970), even though its role in primates (Dym 1973) and perhaps humans is considerably diminished. In short, these findings demonstrate that the entry of adjudin into the apical compartment of the seminiferous epithelium is mediated almost exclusively by drug transporters instead of via paracellular diffusion at the TJ barrier. Thus, these findings require additional studies to examine whether the transport of other drugs and/or chemicals across the BTB is similarly regulated. Additionally, it remains to be determined if a knockdown of efflux pumps (e.g. P-glycoprotein) would impede the Sertoli TJ permeability barrier function.

\section{Concluding remarks}

It must be noted that the above findings regarding the role of efflux pumps in mediating drug transport across the BTB is based on the use of an in vitro model of Sertoli cell BTB. Yet, it is also noted that many of the earlier findings using this in vitro model to study BTB regulation, such as the regulation of Sertoli cell TJ permeability barrier function in vitro by TGF$\beta 3$ (Lui et al. 2001) is mediated via the p38 MAPK signaling 
pathway downstream (Lui et al. 2003a), have subsequently been confirmed and validated in studies in vivo (Lui et al. 2003b, Wong et al. 2004). This is not entirely unexpected because multiple laboratories have been using this in vitro primary Sertoli cell culture system to investigate the biology and regulation of BTB dynamics including our laboratory (Byers et al. 1986, Grima et al. 1992, Janecki et al. 1992, Okanlawon \& Dym 1996, Chung \& Cheng 2001, Li et al. 2001b), and many of these findings were subsequently confirmed in studies in vivo (Hew et al. 1993, Lui et al. 2003b, Wong et al. 2005). Nonetheless, these findings reported in this study require additional in vivo studies for their validation.

\section{Declaration of interest}

The authors declare that there is no conflict of interest that could be perceived as prejudicing the impartiality of the research reported.

\section{Funding}

This research was supported by grants from the National Institutes of Health (NICHD, R01 HD056034 and R01 HD056034-02-S1 to C Y C; U54 HD029990 Project 5 to C Y C; R03 HD 061401 to DDM); and Research Grant Councils and Committee for Research and Conference Grants (CRGG) of the University of Hong Kong to WML.

\section{Acknowledgements}

We thank Dr Elissa W P Wong for her helpful suggestions in performing the real-time quantitative PCR experiments and her help in analyzing the qPCR data.

\section{References}

Abe T, Kakyo M, Sakagami H, Tokui T, Nishio T, Tanemoto M, Nomura H, Hebert SC, Matsuno S, Kondo H et al. 1998 Molecular characterization and tissue distribution of a new organic anion transporter subtype (oatp3) that transports thyroid hormones and taurocholate and comparison with oatp2. Journal of Biological Chemistry 273 22395-22401. (doi:10.1074/jbc. 273.35.22395)

Augustine LM, Markelewicz RJJ, Boekelheide K \& Cherrington NJ 2005 Xenobiotic and endobiotic transporter mRNA expression in the bloodtestis barrier. Drug Metabolism and Disposition 33 182-189. (doi:10.1124/ dmd.104.001024)

Byers S, Hadley M, Djakiew D \& Dym M 1986 Growth and characterization of epididymal epithelial cells and Sertoli cells in dual environment culture chambers. Journal of Andrology 7 59-68.

Cattori V, van Montfoort JE, Stieger B, Landmann L, Meijer DKF, Winterhalter KH, Meier PJ \& Hagenbuch B 2001 Localization of organic anion transporting polypeptide 4 (Oatp4) in rat liver and comparison of its substrate specificity with Oatp1, Oatp2 and Oatp3. Pflügers Archiv: European Journal of Physiology 443 188-195. (doi:10.1007/s004240100697)

Cheng CY \& Mruk DD 2002 Cell junction dynamics in the testis: Sertoligerm cell interactions and male contraceptive development. Physiological Reviews 82 825-874. (doi:10.1152/physrev.00009.2002)

Cheng CY \& Mruk DD 2010 A local autocrine axis in the testes that regulates spermatogenesis. Nature Reviews. Endocrinology 6 380-395. (doi:10.1038/ nrendo.2010.71)
Cheng CY, Mather JP, Byer AL \& Bardin CW 1986 Identification of hormonally responsive proteins in primary Sertoli cell culture medium by anion-exchange high performance liquid chromatography. Endocrinology 118 480-488. (doi:10.1210/endo-118-2-480)

Cheng CY, Silvestrini B, Grima J, Mo MY, Zhu LJ, Johansson E, Saso L, Leone MG, Palmery M \& Mruk DD 2001 Two new male contraceptives exert their effects by depleting germ cells prematurely from the testis. Biology of Reproduction 65 449-461. (doi:10.1095/biolreprod65.2.449)

Cheng CY, Mruk DD, Silvestrini B, Bonanomi M, Wong CH, Siu MKY, Lee NPY \& Mo MY 2005 AF-2364 [1-(2,4-dichlorobenzyl)-1H-indazole3 -carbohydrazide] is a potential male contraceptive: a review of recent data. Contraception 72 251-261. (doi:10.1016/j.contraception.2005.03.008)

Cheng CY, Wong EWP, Lie PPY, Li MWM, Su L, Siu ER, Yan HHN, Mannu J, Mathur PP, Bonanomi M et al. 2011 Environmental toxicants and male reproductive function. Spermatogenesis 1 2-13. (doi:10.4161/ spmg.1.1.13971)

Chung NPY \& Cheng CY 2001 Is cadmium chloride-induced inter-Sertoli tight junction permeability barrier disruption a suitable in vitro model to study the events of junction disassembly during spermatogenesis in the rat testis? Endocrinology 142 1878-1888. (doi:10.1210/en.142.5.1878)

Collarini EJ, Kuhn R, Marshall CJ, Monuki ES, Lemke G \& Richardson WD 1992 Down-regulation of the POU transcription factor SCIP is an early event in oligodendrocyte differentiation in vitro. Development 116 193-200.

Dallas S, Miller DS \& Bendayan R 2006 Multidrug resistance-associated proteins: expression and function in the central nervous system. Pharmacological Reviews 58 140-161. (doi:10.1124/pr.58.2.3)

Dym M 1973 The fine structure of the monkey (Macaca) Sertoli cell and its role in maintaining the blood-testis barrier. Anatomical Record 175 639-656. (doi:10.1002/ar.1091750402)

Dym M \& Fawcett DW 1970 The blood-testis barrier in the rat and the physiological compartmentation of the seminiferous epithelium. Biology of Reproduction 3 308-326.

El-Sheikh AA, Masereeuw R \& Russel FG 2008 Mechanisms of renal anionic drug transport. European Journal of Pharmacology 585 245-255. (doi:10. 1016/j.ejphar.2008.02.085)

Fawcett DW, Leak LV \& Heidger PM 1970 Electron microscopic observations on the structural components of the blood-testis barrier. Journal of Reproduction and Fertility 10 (Supplement) 105-122.

Grima J, Pineau C, Bardin CW \& Cheng CY 1992 Rat Sertoli cell clusterin, $\alpha_{2}$-macroglobulin, and testins: biosynthesis and differential regulation by germ cells. Molecular and Cellular Endocrinology 89 127-140. (doi:10.1016/ 0303-7207(92)90219-V)

Grima J, Wong CC, Zhu LJ, Zong SD \& Cheng CY 1998 Testin secreted by Sertoli cells is associated with the cell surface, and its expression correlates with the disruption of Sertoli-germ cell junctions but not the inter-Sertoli tight junction. Journal of Biological Chemistry 273 21040-21053. (doi:10. $1074 / \mathrm{jbc} .273 .33 .21040)$

Hew KW, Heath GL, Jiwa AH \& Welsh MJ 1993 Cadmium in vivo causes disruption of tight junction-associated microfilaments in rat Sertoli cells. Biology of Reproduction 49 840-849. (doi:10.1095/biolreprod49.4.840)

Hu GX, Hu LF, Yang DZ, Li JW, Chen GR, Chen BB, Mruk DD, Bonanomi M, Silvestrini B, Cheng CY et al. 2009 Adjudin targeting rabbit germ cell adhesion as a male contraceptive: a pharmacokinetics study. Journal of Andrology 30 87-93. (doi:10.2164/jandrol.108.004994)

Janecki A \& Steinberger A 1986 Polarized Sertoli cell functions in a new two-compartment culture system. Journal of Andrology 7 69-71.

Janecki A, Jakubowiak A \& Steinberger A 1991a Effects of cyclic AMP and phorbol ester on transepithelial electrical resistance of Sertoli cell monolayers in two-compartment culture. Molecular and Cellular Endocrinology 82 61-69. (doi:10.1016/0303-7207(91)90009-H)

Janecki A, Jakubowiak A \& Steinberger A $1991 b$ Regulation of transepithelial electrical resistance in two-compartment Sertoli cell cultures: in vitro model of the blood-testis barrier. Endocrinology 129 1489-1496. (doi:10.1210/ endo-129-3-1489)

Janecki A, Jakubowiak A \& Steinberger A 1992 Effect of cadmium chloride on transepithelial electrical resistance of Sertoli cell monolayers in two- 
compartment cultures - a new model for toxicological investigations of the "blood-testis" barrier in vitro. Toxicology and Applied Pharmacology 112 51-57. (doi:10.1016/0041-008X(92)90278-Z)

Kis O, Robillard K, Chan GN \& Bendayan R 2010 The complexities of antiretroviral drug-drug interactions: role of $\mathrm{ABC}$ and SLC transporters. Trends in Pharmacological Sciences 31 22-35. (doi:10.1016/j.tips.2009.10.001)

Klaassen CD \& Aleksunes LM 2010 Xenobiotic, bile acid, and cholesterol transporters: function and regulation. Pharmacological Reviews 62 1-96. (doi:10.1124/pr.109.002014)

Li JCH, Lee WM, Mruk DD \& Cheng CY 2001a Regulation of Sertoli cell myotubularin (rMTM) expression by germ cells in vitro. Journal of Andrology 22 266-277.

Li JCH, Mruk DD \& Cheng CY $2001 b$ The inter-Sertoli tight junction permeability barrier is regulated by the inter-play of protein phosphatases and kinases: an in vitro study. Journal of Andrology 22 847-856.

Li MWM, Xia W, Mruk DD, Wang CQF, Yan HHY, Siu MKY, Lui WY, Lee WM \& Cheng CY 2006 TNF $\alpha$ reversibly disrupts the blood-testis barrier and impairs Sertoli-germ cell adhesion in the seminiferous epithelium of adult rat testes. Journal of Endocrinology 190 313-329. (doi:10. 1677/joe.1.06781)

Li MWM, Mruk DD, Lee WM \& Cheng CY 2009 Connexin 43 and plakophilin-2 as a protein complex that regulates blood-testis barrier dynamics. PNAS 106 10213-10218. (doi:10.1073/pnas. 0901700106)

Lie PPY, Cheng CY \& Mruk DD 2010 Crosstalk between desmoglein2/desmocollin-2/Src kinase and coxsackie and adenovirus receptor/ZO-1 protein complexes, regulates blood-testis barrier dynamics. International Journal of Biochemistry and Cell Biology 42 975-986. (doi:10.1016/j.biocel. 2010.02.010)

Lui WY, Lee WM \& Cheng CY 2001 Transforming growth factor- $\beta 3$ perturbs the inter-Sertoli tight junction permeability barrier in vitro possibly mediated via its effects on occludin, zonula occludens-1, and claudin- 11 . Endocrinology 142 1865-1877. (doi:10.1210/en.142.5.1865)

Lui WY, Lee WM \& Cheng CY 2003a Transforming growth factor- $\beta 3$ regulates the dynamics of Sertoli cell tight junctions via the p38 mitogenactivated protein kinase pathway. Biology of Reproduction 68 1597-1612. (doi:10.1095/biolreprod.102.011387)

Lui WY, Wong CH, Mruk DD \& Cheng CY $2003 b$ TGF- $\beta 3$ regulates the blood-testis barrier dynamics via the p38 mitogen activated protein (MAP) kinase pathway: an in vivo study. Endocrinology 144 1139-1142. (doi:10. 1210/en.2002-0211)

Meier PJ \& Stieger B 2002 Bile salt transporters. Annual Review of Physiology 64 635-661. (doi:10.1146/annurev.physiol.64.082201.100300)

Meinhardt A \& Hedger MP 2010 Immunological, paracrine and endocrine aspects of testicular immune privilege. Molecular and Cellular Endocrinology 335 60-68. (doi:10.1016/j.mce.2010.03.022)

Miller DS, Bauer B \& Hartz AM 2008 Modulation of P-glycoprotein at the blood-brain barrier: opportunities to improve central nervous system pharmacotherapy. Pharmacological Reviews 60 196-209. (doi:10.1124/pr. 107.07109)

Mizuno N, Niwa T, Yotsumoto Y \& Sugiyama Y 2003 Impact of drug transporter studies on drug discovery and development. Pharmacological Reviews 55 425-461. (doi:10.1124/pr.55.3.1)

Mruk DD \& Cheng CY 2008 Delivering non-hormonal contraceptives to men: advances and obstacles. Trends in Biotechnology 26 90-99. (doi:10. 1016/j.tibtech.2007.10.009)

Mruk DD, Zhu LJ, Silvestrini B, Lee WM \& Cheng CY 1997 Interactions of proteases and protease inhibitors in Sertoli-germ cell cocultures preceding the formation of specialized Sertoli-germ cell junctions in vitro. Journal of Andrology 18 612-622.

Mruk DD, Siu MKY, Conway AM, Lee NPY, Lau ASN \& Cheng CY 2003 Role of tissue inhibitor of metalloproteases- 1 in junction dynamics in the testis. Journal of Andrology 24 510-523.

Mruk DD, Wong CH, Silvestrini B \& Cheng CY 2006 A male contraceptive targeting germ cell adhesion. Nature Medicine 12 1323-1328. (doi:10.1038/ nm1420)
Mruk DD, Silvestrini B \& Cheng CY 2008 Anchoring junctions as drug targets: role in contraceptive development. Pharmacological Reviews $\mathbf{6 0}$ 146-180. (doi:10.1124/pr.107.07105)

O'Donnell L, Nicholls PK, O’Bryan MK, McLachlan RI \& Stanton PG 2011 Spermiation. The process of sperm release. Spermatogenesis 1 14-35. (doi:10.4161/spmg.1.1.14525)

Ohtsuki S, Takizawa T, Takanaga H, Hori S, Hosoya KI \& Terasaki T 2004 Localization of organic anion transporting polypeptide 3 (oatp3) in mouse brain parenchymal and capillary endothelial cells. Journal of Neurochemistry 90 743-749. (doi:10.1111/j.1471-4159.2004.02549.x)

Okanlawon A \& Dym M 1996 Effect of chloroquine on the formation of tight junctions in cultured immature rat Sertoli cells. Journal of Andrology 17 249-255.

Orth JM 1982 Proliferation of Sertoli cells in fetal and postnatal rats: a quantitative autoradiographic study. Anatomical Record 203 485-492. (doi:10.1002/ar.1092030408)

Rochat B 2009 Importance of influx and efflux systems and xenobiotic metabolizing enzymes in intratumoral disposition of anticancer agents. Current Cancer Drug Targets 9 652-674. (doi:10.2174/156800909789056999)

Setchell BP 2008 Blood-testis barrier, junctional and transport proteins and spermatogenesis. In Molecular Mechanisms in Spermatogenesis, pp 212-233. Ed. CY Cheng. Austin, TX: Landes Bioscience/Springer Science+ Business Media, LLC.

Shen S \& Zhang W 2010 ABC transporters and drug efflux at the blood-brain barrier. Reviews in the Neurosciences 21 29-53. (doi:10.1515/REVNEURO. 2010.21.1.29)

Siu MKY, Lee WM \& Cheng CY 2003 The interplay of collagen IV, tumor necrosis factor- $\alpha$, gelatinase B (matrix metalloprotease-9), and tissue inhibitor of metalloprotease- 1 in the basal lamina regulates Sertoli cell-tight junction dynamics in the rat testis. Endocrinology 144 371-387. (doi:10. 1210/en.2002-220786)

Siu MKY, Wong CH, Lee WM \& Cheng CY 2005 Sertoli-germ cell anchoring junction dynamics in the testis are regulated by an interplay of lipid and protein kinases. Journal of Biological Chemistry 280 25029-25047. (doi:10.1074/jbc.M501049200)

Siu ER, Wong EWP, Mruk DD, Porto CS \& Cheng CY 2009a Focal adhesion kinase is a blood-testis barrier regulator. PNAS 106 9298-9303. (doi:10. 1073/pnas.0813113106)

Siu ER, Wong EWP, Mruk DD, Sze KL, Porto CS \& Cheng CY 2009b An occludin-focal adhesion kinase protein complex at the blood-testis barrier: a study using the cadmium model. Endocrinology 150 3336-3344. (doi:10. 1210/en.2008-1741)

Siu MKY, Wong CH, Xia W, Mruk DD, Lee WM \& Cheng CY 2011 The B1-integrin-p-FAK-p130Cas-DOCK180-RhoA-vinculin is a novel regulatory protein complex at the apical ectoplasmic specialization in adult rat testes. Spermatogenesis 1 73-86. (doi:10.4161/spmg.1.1.15452)

Su L, Cheng CY \& Mruk DD 2009 Drug transporter, P-glycoprotein (MDR1), is an integrated component of the mammalian blood-testis barrier. International Journal of Biochemistry and Cell Biology 41 2578-2587. (doi:10.1016/j.biocel.2009.08.015)

Su L, Cheng CY \& Mruk DD 2010a Adjudin-mediated Sertoli-germ cell junction disassembly affects Sertoli cell barrier function in vitro and in vivo. International Journal of Biochemistry and Cell Biology 42 1864-1875. (doi:10. 1016/j.biocel.2010.08.004)

Su L, Mruk DD \& Cheng CY $2010 b$ Drug transporters, the blood-testis barrier, and spermatogenesis. Journal of Endocrinology 208 207-223. (doi:10. 1677/JOE-10-0363)

Su L, Mruk DD, Lee WM \& Cheng CY 2010c Differential effects of testosterone and TGF- $\beta 3$ on endocytic vesicle-mediated protein trafficking events at the blood-testis barrier. Experimental Cell Research 316 2945-2960. (doi:10.1016/j.yexcr.2010.07.018)

Suzuki T, Onogawa T, Asano N, Mizutamari H, Mikkaichi T, Tanemoto M, Abe M, Satoh F, Unno M, Nunoki K et al. 2003 Identification and characterization of novel rat and human gonad-specific organic anion transporters. Molecular Endocrinology 17 1203-1215. (doi:10.1210/me.2002-0304)

Ueno M, Nakagawa T, Wu B, Onodera M, Huang CL, Kusaka T, Araki N \& Sakamoto H 2010 Transporters in the brain endothelial barrier. Current Medicinal Chemistry 17 1125-1138. (doi:10.2174/092986710790827816) 
Wong CH, Mruk DD, Lui WY \& Cheng CY 2004 Regulation of blood-testis barrier dynamics: an in vivo study. Journal of Cell Science 117 783-798. (doi:10.1242/jcs.00900)

Wong CH, Mruk DD, Siu MKY \& Cheng CY 2005 Blood-testis barrier dynamics are regulated by $\alpha 2$-macroglobulin via the c-Jun $\mathrm{N}$-terminal protein kinase pathway. Endocrinology 146 1893-1908. (doi:10.1210/en.2004-1464)

Wong EWP, Mruk DD \& Cheng CY 2008a Biology and regulation of ectoplasmic specialization, an atypical adherens junction type, in the testis. Biochimica et Biophysica Acta 1778 692-708. (doi:10.1016/j.bbamem.2007. 11.006)

Wong EWP, Mruk DD, Lee WM \& Cheng CY 20086 Par3/Par6 polarity complex coordinates apical ectoplasmic specialization and blood-testis barrier restructuring during spermatogenesis. PNAS 105 9657-9662. (doi:10.1016/j.bbamem.2007.11.006)

Xia W, Mruk DD, Lee WM \& Cheng CY 2007 Unraveling the molecular targets pertinent to junction restructuring events during spermatogenesis using the Adjudin-induced germ cell depletion model. Journal of Endocrinology 192 563-583. (doi:10.1677/JOE06-0158)

Xia W, Wong EWP, Mruk DD \& Cheng CY 2009 TGF- $\beta 3$ and TNF $\alpha$ perturb blood-testis barrier (BTB) dynamics by accelerating the clathrin-mediated endocytosis of integral membrane proteins: a new concept of BTB regulation during spermatogenesis. Developmental Biology 327 48-61. (doi:10.1016/ j.ydbio.2008.11.028)

Yan HHN \& Cheng CY 2006 Laminin $\alpha 3$ forms a complex with $\beta 3$ and $\gamma 3$ chains that serves as the ligand for $\alpha 6 \beta 1$-integrin at the apical ectoplasmic specialization in adult rat testes. Journal of Biological Chemistry 281 17286-17303. (doi:10.1074/jbc.M513218200)

Yan HHN, Mruk DD, Lee WM \& Cheng CY 2008a Blood-testis barrier dynamics are regulated by testosterone and cytokines via their differential effects on the kinetics of protein endocytosis and recycling in Sertoli cells FASEB Journal 22 1945-1959. (doi:10.1096/fj.06-070342)

Yan HHN, Mruk DD, Wong EWP, Lee WM \& Cheng CY $2008 b$ An autocrine axis in the testis that coordinates spermiation and blood-testis barrier restructuring during spermatogenesis. PNAS 105 8950-8955. (doi:10.1073/pnas.0711264105)

Received in final form 5 March 2011

Accepted 6 April 2011

Made available online as an Accepted Preprint 6 April 2011 